\title{
Failure of high strength steel sheets: Experiments and modelling
}

\author{
Oscar Björklund, Rikard Larsson and Larsgunnar Nilsson
}

\section{Linköping University Post Print}

\section{Tweet}

N.B.: When citing this work, cite the original article.

Original Publication:

Oscar Björklund, Rikard Larsson and Larsgunnar Nilsson, Failure of high strength steel sheets: Experiments and modelling, 2013, Journal of Materials Processing Technology, (213), 7, 1103-1117.

http://dx.doi.org/10.1016/j.jmatprotec.2013.01.027

Copyright: Elsevier

http://www.elsevier.com/

Postprint available at: Linköping University Electronic Press

http://urn.kb.se/resolve?urn=urn:nbn:se:liu:diva-77758 


\title{
Failure of high strength steel sheets - Experiments and modelling
}

\author{
Oscar Björklund*, Rikard Larsson, Larsgunnar Nilsson \\ Division of Solid Mechanics, Department of Management and Engineering, Linköpings \\ University, SE-581 83 Linköping, Sweden
}

\begin{abstract}
Failure in sheet metal structures of ductile material is usually caused by one of, or a combination of, ductile fracture, shear fracture or localised instability. In this paper the failure of the high strength steel Docol 600DP and the ultra high strength steel Docol $1200 \mathrm{M}$ is explored. The constitutive model used in this study includes plastic anisotropy and mixed isotropic-kinematic hardening. For modelling of the ductile and shear fracture the models presented by Cockroft-Latham and Bressan-Williams have been used. The instability phenomenon is described by the constitutive law and the finite element (FE) models. For calibration of the failure models and validation of the results, an extensive experimental series has been conducted including shear tests, plane strain tests and Nakajima tests. The geometries of the Nakajima tests have been chosen so that the first quadrant of the forming limit diagram (FLD) were covered. The results are presented both in an FLD and using prediction of force-displacement response of the Nakajima test employing element erosion during the FE simulations. The classical approach for failure prediction is to compare the principal plastic strains obtained from FE simulations with experimental determined forming limit curves (FLC). It is well known that the experimental FLC requires proportional strains to be useful. In this work failure criteria, both of the instability and fracture, are proposed which can be used also for non-proportional strain paths.
\end{abstract}

Keywords: sheet metal failure, high strength steels, forming limits, ductile fracture, shear fracture

*Corresponding author. Tel.:+46-13281111; fax:+46-13282717.

Email address: oscar.bjorklund@liu.se (Oscar Björklund) 


\section{Introduction}

The demand for more advanced sheet metals with both high strength and good ductility is continuously increasing. In this study two steels are studied: one high strength steel (HSS), Docol 600DP, and one ultra high strength steel (UHSS), Docol 1200M, Olsson et al. (2006). A constitutive model has been developed and calibrated for these steels, see Larsson et al. (2011). In this work this model is further developed and investigated concerning its ability to predict material fracture.

Fracture can generally be either ductile or brittle. However, the steels in this study exhibit a ductile fracture in all applications of interest. Several different phenomena may contribute to the failure process. In Teirlinck et al. (1988) four failure phenomena observed in uniaxial tension specimens are described: (1) plastic failure, (2) ductile fracture, (3) shear fracture and (4) cleavage and brittle intergranular fracture. It should be noted that failure type (4), cleavage and brittle intergranular fracture, is considered as a brittle fracture, which is not covered here. From a micromechanical point of view, the ductile fracture is characterised by the establishment, growth and coalescence of voids in the material, and eventually the load-bearing capacity is sufficiently reduced for the material to fail. The reduction in load-bearing capacity due to void growth leads to material softening. In damage mechanics this effect is regarded as a damage accumulation, c.f. Gurson (1977) and Lemaitre (1985). Most fracture models, on the other hand, do not affect the constitutive laws before fracture, but apply first when some limit state is reached. Numerous fracture models have been presented, see e.g. Wierzbicki et al. (2005) for a summary of a few of them.

The first three failure types presented by Teirlinck et al. (1988) are also identified for sheet metals in Hooputra et al. (2004), but the term plastic failure is generalised to represent any sheet instability. Prediction of sheet instability due to localisation was studied early in analytical models by Hill (1952) and Swift (1952). Hora et al. (1996) presented a more general analytic instability model. For a recent review, see Aretz (2004). However, also models based on non-homogeneous sheets have been used to predict localisation, see Marciniak and Kuczynski (1967). Due to the increased computational power, detailed finite element (FE) models with elasto-plastic or elasto-viscoplastic constitutive laws can be used to capture instability phenomena in details, c.f. Lademo et al. (2004a).

Several phenomenological models for predicting ductile fracture have been 
presented. The Cockroft and Latham (1968) criterion is a modified maximum plastic work criterion based on the maximum principal stress. Oyane et al. (1980) presented a model which depends on the stress triaxiality and the equivalent plastic strain. In Wilkins et al. (1980) the fracture criterion is a function of both the hydrostatic pressure, the deviator stress and the equivalent plastic strain. In Johnson and Cook (1985) the fracture criterion depends on stress traxiality, strain rate, temperature and equivalent plastic strain.

Shear fracture can be caused either by extensive slip on the activated slip planes, see Dieter (1986), or as a result of void nucleation in the slip bands. Both of these mechanisms are favoured by shear stresses. When voids nucleate in the slip bands, the loaded area is reduced such that plastic flow localises there. Continued shear increases the area of the voids until separation occurs. Furthermore, as stated by Teirlinck et al. (1988) "Voids which extend in shear need not increase in volume, so shear fracture is less pressure-dependent than ductile fracture, though it remains more pressuredependent than purely-plastic failure". Models for predicting shear fracture in sheet metals are presented, e.g. by Li et al. (2010). Bressan and Williams (1983) describe a method for predicting localised necking by the use of a through thickness shear criterion for the plane stress case.

The forming limit diagram (FLD) has been a very popular mean of predicting failure in sheet metals. The locus of all principal plastic strain combinations at the onset of failure defines the so called forming limit curve (FLC). However, the FLC is a good measure of failure only at proportional straining, since the FLC depends on the history of straining, c.f. Hosford and Cadell (1993). In this work the fracture is described by phenomenological models which can be considered throughout the complete simulation process. Thus, the fracture can be predicted e.g. in a crash event where the components have inherited properties from the forming operations.

Many phenomenological models for predicting failure and fracture have been presented over the years, see e.g. Nielsen (2000) for a review of some of them. The importance of stress triaxiality on the ductility has been demonstrated by several authors, e.g. Bao and Wierzbicki (2004). Also dependency on the Lode parameter has been reported by, e.g. Bai and Wierzbicki (2008). Several papers have been presented on different models for predicting fracture in sheet metals, e.g. Han and Kim (2003) used a combination of the models presented by Cockroft and Latham (1968) and Bressan and Williams (1983) for predicting ductile fracture in sheet metals. Lademo et al. (2009) 
presented a numerical and experimental study on fracture in an aluminium alloy. Gruben et al. (2011) studied the fracture characteristics of a coldrolled dual-phase steel using FE simulations and digital image correlation (DIC). The special case of shear fracture in sheet metals has been studied by, e.g. Kim et al. (2011).

In this paper phenomenological fracture models are used for predicting ductile fracture in sheet metals. The different fracture mechanisms and models are briefly presented in Section 2, followed by a presentation of the experimental programme. The constitutive equations are briefly presented in Section 4. The FE simulations of the experimental set-ups and parameter identifications are presented in Sections 5 and 6, respectively.

\section{Failure Models}

In thin ductile metal sheets, failure can be caused by ductile fracture, shear fracture or instability due to localisation, or a combination of these failures, see Figure 1. Since the different failure phenomena are caused by different mechanisms, it may be useful to use different models to capture these phenomena.



(a)

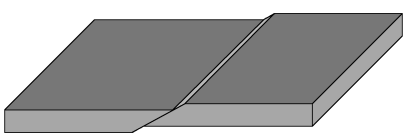

(b)

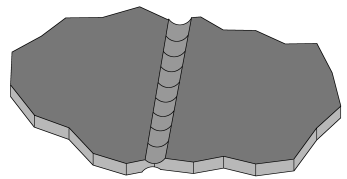

(c)

Figure 1: Failure in ductile sheet metals, (a) ductile fracture, (b) shear fracture and (c) instability with localized necking.

\subsection{Ductile fracture}

The ductile fracture is described by the initiation, growth and coalescence of voids in the material, and eventually the load-bearing capacity may be reduced such that fracture occures. The successive reduction in load-bearing capacity causes material softening which phenomenon, however, will not be considered in this study. Also when constructing fracture models, which do not affect the constitutive laws, it is sometimes useful to consider the fracture 
criterion as a damage variable which grows during the deformation. A basic form of a fracture criterion is

$$
\int_{0}^{\varepsilon_{f}} f(\boldsymbol{\sigma}, \boldsymbol{\varepsilon}, \dot{\varepsilon}, T, \ldots) \mathrm{d} \bar{\varepsilon}^{p} \leq C
$$

where $\varepsilon_{f}$ is the strain at fracture and $C$ is a material parameter. This expression can be formulated as a damage model.

$$
D=\frac{1}{C} \int_{0}^{\varepsilon_{f}} f(\boldsymbol{\sigma}, \varepsilon, \dot{\varepsilon}, T, \ldots) \mathrm{d} \bar{\varepsilon}^{p} \leq 1
$$

The function $f$ may depend on internal variables, often stress, strain, strain-rate and temperature. Different weighting functions $f$ yield several well-known fracture models, e.g

$$
f= \begin{cases}1 & \text { max effective strain criterion } \\ \bar{\sigma} & \text { max plastic work criterion } \\ \max \left(\sigma_{1}, 0\right) & \text { Cockroft and Latham (1968) criterion } \\ \frac{\sigma_{m}}{\sigma_{v M}}+C_{1} & \text { Oyane et al. (1980) criterion }\end{cases}
$$

As stated by Teirlinck et al. (1988), the ductile fracture is caused by certain combinations of the strain and stress states rather then either of these states separately. The plastic work prior to fracture has been argued to be an important factor. However, the fracture condition is also related to the hydrostatic pressure, and since the plastic deformation of most metals is pressure insensitive, the plastic work prior to fracture will disregard this effect. Cockroft and Latham (1968) suggested a modification of the plastic work, which considers the maximum tensile stress

$$
W=\int_{0}^{\varepsilon_{f}} \frac{\left\langle\sigma_{1}\right\rangle}{\bar{\sigma}} \bar{\sigma} \mathrm{d} \bar{\varepsilon}^{p} \leq W_{c}
$$

where $\left\langle\sigma_{1}\right\rangle=\max \left(\sigma_{1}, 0\right)$ is the largest tensile stress. The principal stress, $\sigma_{1}$, can be expressed as a function of the hydrostatic pressure, $p=-\frac{1}{3} \operatorname{tr} \boldsymbol{\sigma}$, the second invariant of the stress deviator, $J_{2}=\frac{1}{2} s: s$ and the Lode angle, $\theta$ where $\cos 3 \theta=\frac{\sqrt{27}}{2} \frac{J_{3}}{J_{2}^{3 / 2}}$ and $J_{3}=\operatorname{dets}$.

$$
\sigma_{1}=-p+\sqrt{\frac{4 J_{2}}{3}} \cos \theta
$$


Thus, in the Cockroft-Latham criterion the fracture depends on the hydrostatic pressure, the second stress deviator invariant and the Lode angle in addition to the equivalent plastic strain. Fracture is expected to occur when the integral in Equation 3 reaches the critical value $W_{c}$.

\subsection{Shear fracture}

Since the classical shell elements used for sheet metal applications are restricted to plane stress situations, they are not able to describe shear stresses through their thickness. Thus, there is a need to include a model for predicting shear fracture for a plane stress state. Bressan and Williams (1983) suggested that the plastic strain increment should be equal to zero at an inclined direction through the thickness of the sheet during this shear failure. By assuming that the directions of principal stress and strain coincide, the limit shear stress on the inclined surface can be expressed as

$$
\tau=\frac{\sigma_{1}}{2} \sqrt{1-\left(\frac{-\beta}{2+\beta}\right)^{2}} \leq \tau_{c}
$$

where $\sigma_{1}$ is the largest in plane principal stress and $\beta=\mathrm{d} \varepsilon_{2}^{p} / \mathrm{d} \varepsilon_{1}^{p}$ is the relation between the in-plane principal plastic strains. However, in this work a stress in the thickness direction has been introduced in order to obtain a $C^{0}$ continuous element thickness formulation, see Section 4 . Thus, the expression for the critical-through-thickness shear stress has been modified as

$$
\tau=\frac{\sigma_{1}-\sigma_{33}}{2} \sqrt{1-\left(\frac{-\beta}{2+\beta}\right)^{2}} \leq \tau_{c}
$$

where $\sigma_{33}$ is the stress in the thickness direction. Fracture is expected to occur when the critical shear stress, $\tau_{c}$ is reached, i.e. when the equality of Equation 6 is meet.

\subsection{Numerical prediction of instability}

Plastic instability may occur in thin-walled sheet applications. For an accurate FE prediction of instability, the mesh in the localised zone needs

to be dense, since the size of the localisation zone is of the same order as the sheet thickness, cf. Dieter (1986). If a larger element size is used it is necessary to introduce an analytical model or a limit curve to predict the 
onset of instability. In an FE simulation introduction of a disturbance is often efficient, i.e. a variation in the thickness or in a constitutive parameter, to trigger the instability and obtain realistic results. Lademo et al. (2004a) describe the thickness variation for a square patch of elements with the use of a normal distributed random field. However, according to Fyllingen et al. (2009) one drawback of this method is that the variation depends on the number of nodes. Hence, a refinement of the FE mesh will lead to a different random field. Consequently the variation in the thickness is described here as a geometrical property independent of the FE mesh.

$$
t(x, y)=\mu(x, y)+Z(x, y)
$$

In Equation 7 both the mean thickness value, $\mu$, and the residual term, $Z$, may depend on the global in-plane coordinates $x$ and $y$. In this work the mean value has been set to a constant and a Gaussian zero mean homogeneous random field according to Shinozuka and Deodatis (1996) has been used for the residual term. The parameters representing the Gaussian zero mean homogeneous random field has been chosen heuristically in order to obtain a similar thickness variation as is observed in the measurements.

At the instability, most deformation is concentrated to the localised zone and the ultimate fracture will be quickly achieved. In forming applications, the instability limit is often also regarded as a limit for the forming even if no material separation takes place. Moreover, the FLD is useful in order to compare different failure models. An FE method for predicting instability by Lademo et al. (2004a) and Lademo et al. (2004b) has been used in this study. A square FE patch is used with an inhomogeneous thickness distribution. The patch is stretched in different directions along its boundaries to obtain linear strain paths. In Lademo et al. (2004a) the limit strains causing localisation are considered as the global strains of the patch when an instability has occurred in any element. However, in this study the local strains in an element within the localisation zone are considered. In order to find the limit strains at localised necking two elements are considered: one inside the localisation and one some distance away from it. The limit strains are then obtained as the strains in the element within the localisation zone when the strain intensity in the distant element does not increase, see Figure 2. It is to be noted that the elastic strains are minor and can be disregarded compared to the plastic strains. 


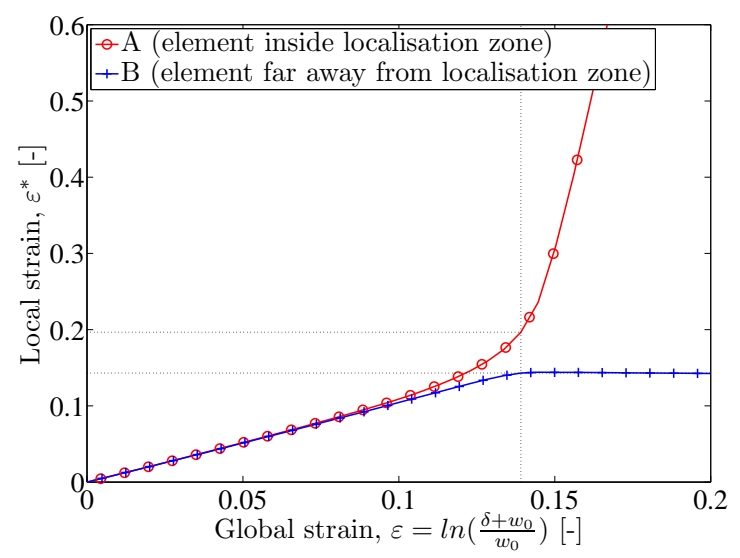

(a)

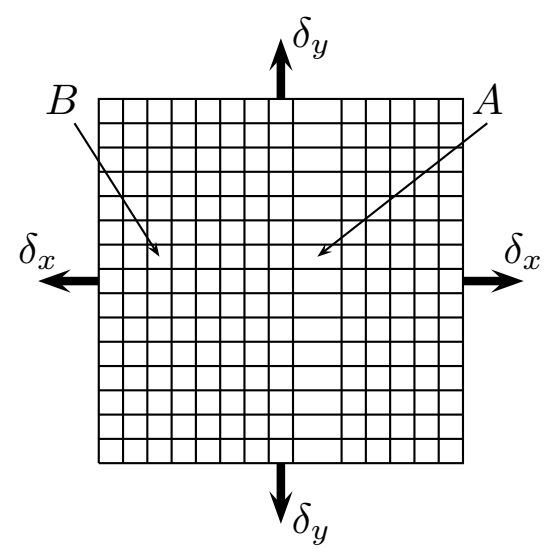

(b)

Figure 2: Evaluation of the instability limit for an element patch (a) strain evaluation and (b) elements $A$ and $B$ selected for evaluation.

\section{Experimental work}

The HSS Docol 600DP, is a dual phase steel with about $75 \%$ ferrite and $25 \%$ martensite, in which the microstructure is produced by heat treatment. The UHSS Docol $1200 \mathrm{M}$, is a fully martensitic steel produced by water quenching from an elevated temperature in the austenitic range, see Olsson et al. (2006). The nominal thicknesses of the Docol 600DP and Docol 1200M steel sheets were $1.48 \mathrm{~mm}$ and $1.46 \mathrm{~mm}$, respectively and the standard deviation of the thickness was measured to be $5.0 \mu \mathrm{m}$ and $4.5 \mu \mathrm{m}$, respectively. An extensive test programme was carried out to characterise the failure and to validate failure predictions. Tensile, bulge and shear tests were realised in different directions to calibrate the constitutive laws. In order to find the fracture parameters shear tests and plane strain tests were used to calibrate the ductile and shear fracture models, respectively. The Nakajima tests, see ISO (2008), with different specimen geometries were used to validate the failure predictions. Since the shear, plane strain and Nakajima tests all were used to calibrate and validate the failure models, these tests only are presented in more detail here. Further information on the additional material tests used to calibrate the constitutive models can be found in Larsson et al. (2011). 


\subsection{Simple in-plane shear tests}

The geometry of the in-plane shear test specimen is shown in Figure 3. The shear tests were performed in the rolling direction (RD), the diagonal direction (DD) and the transversal direction (TD). The three directions correspond to $0^{\circ}, 45^{\circ}$ and $90^{\circ}$ relative to the $\mathrm{RD}$, respectively. The tests were performed in an INSTRON 5582 testing machine with a $10 \mathrm{kN}$ load cell with a displacement rate $0.03 \mathrm{~mm} / \mathrm{min}$. During the test the force applied and the displacement of the grips were recorded. The attachment of the shear test was achieved by using one pin at each end of the specimen to prevent it from introducing rotational loads. The shear specimens failed after a considerable amount of plastic strain and no instability was observed prior to fracture. Therefore this test appears well suited to predict the ductile fracture parameter, $W_{c}$, of the Cockroft-Latham criterion, Equation 3.

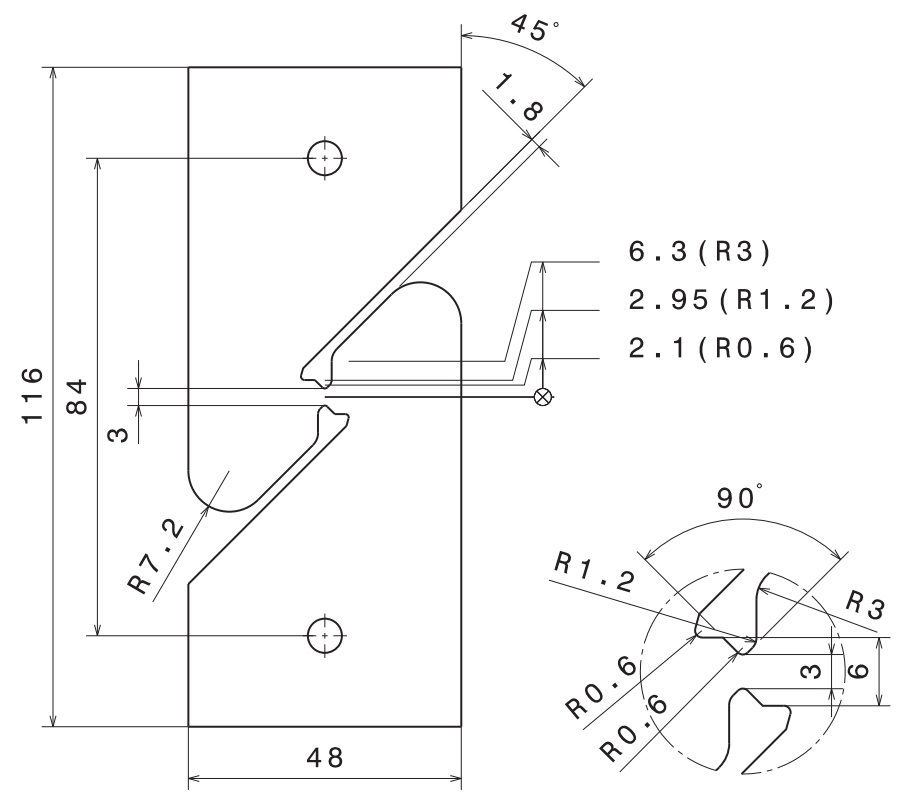

Figure 3: Geometry of the in-plane shear test specimen. Dimensions in mm.

\subsection{Plane strain tests}

The geometry of the plane strain test (notch tensile test) is shown in Figure 4 . These tests were performed in the same testing machine as the shear tests. The displacement rate of $0.06 \mathrm{~mm} / \mathrm{min}$ was used in order to reach 
a strain rate of $10^{-4} s^{-1}$. The plane strain test was also performed in the RD, the DD and the TD. The load, grip motion, width reduction and midsection elongation were measured during the test. The midsection elongation was measured by an INSTRON 2620-601 extensometer with a gauge length of $23 \mathrm{~mm}$, while the width reduction was measured by an MTS 632.19B-20 extensometer. It was found that the fracture surface is inclined through the thickness, which fact indicates a shear fracture. Thus, the Bressan-Williams fracture criterion, according to Equation 6, appears to be suited to predicting this fracture.

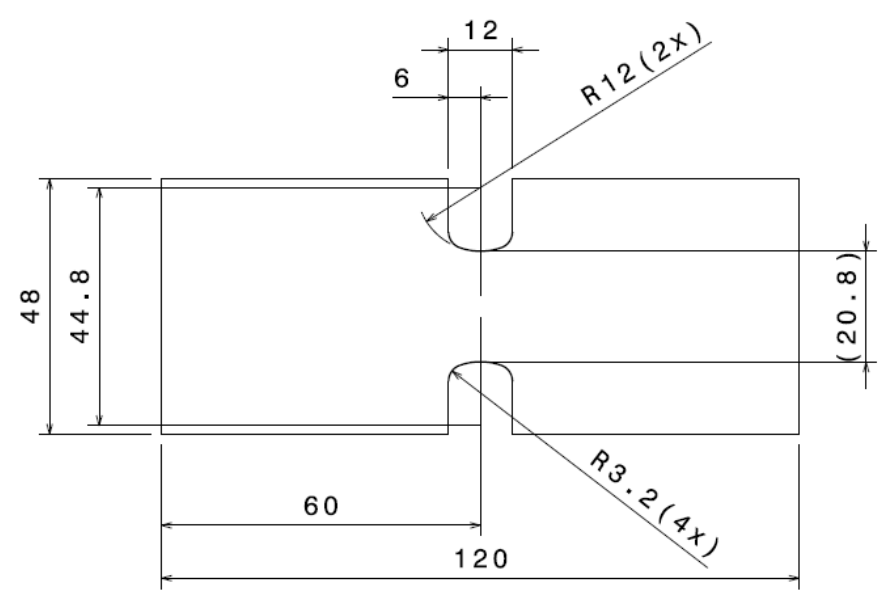

Figure 4: Geometry of the plane strain specimen. Dimensions in $\mathrm{mm}$.

\subsection{Nakajima tests}

In order to evaluate the fracture models a number of Nakajima tests, see ISO (2008), were conducted. The tests were made for different specimen geometries, see Figure 5, to produce strain states such that the first quadrant of the FLD (both principal strains positive) was covered. Specimens were made with the waist both in the sheet RD and transversal to the sheet RD. The Nakajima tests were performed in an Interlaken ServoPress 150, with a punch diameter of $100 \mathrm{~mm}$. The clamping force was limited to $700 \mathrm{kN}$, and the punch motion was set at $1 \mathrm{~mm} / \mathrm{s}$.

A principal sketch of the clamp and punch is shown in Figure 6. The specimens are treated with lubrication oil and three layers of plastic film 
in order to reduce friction between the punch and sheet. On the top sheet surface a $2 \mathrm{~mm}$ grid was etched on the specimens for a subsequent optical evaluation of the strains by an AutoGrid 4.1 Strain Analysis System, which uses information from four cameras recording 30 images per second during the test. The image just before fracture was used to evaluate the limit strains. Since the grid captures the strains close to the fracture, these strains may be beyond the limit of localisation. Consequently a polynomial fit method similar to the one described in Bragard et al. (1972) was used to evaluate the limit strains at the onset of localisation. The strains along a few lines of elements across the localisation band were evaluated. The element inside the localisation zone are then excluded and a polynomial was fitted to the remaining strains in order to find the limit strain causing localisation, see Figure 7 .



Figure 5: The Nakajima specimens with different waist geometries in order to produce different strain paths. The numbers on the specimen specify the width of the waist in $\mathrm{mm}$.

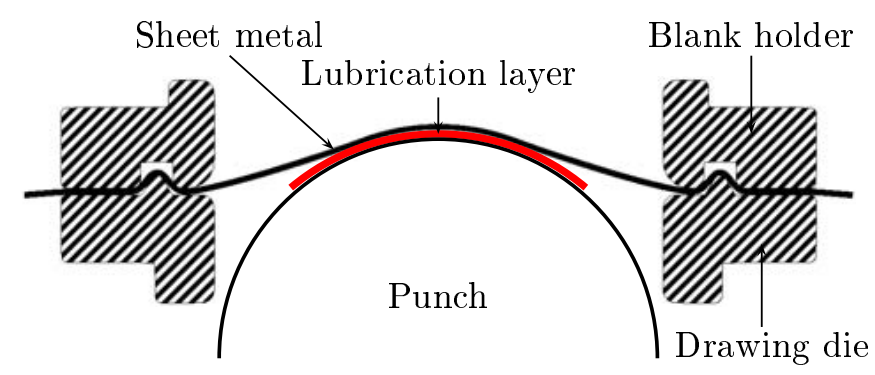

Figure 6: Sketch of the clamp and punch used in the Nakajima test. 


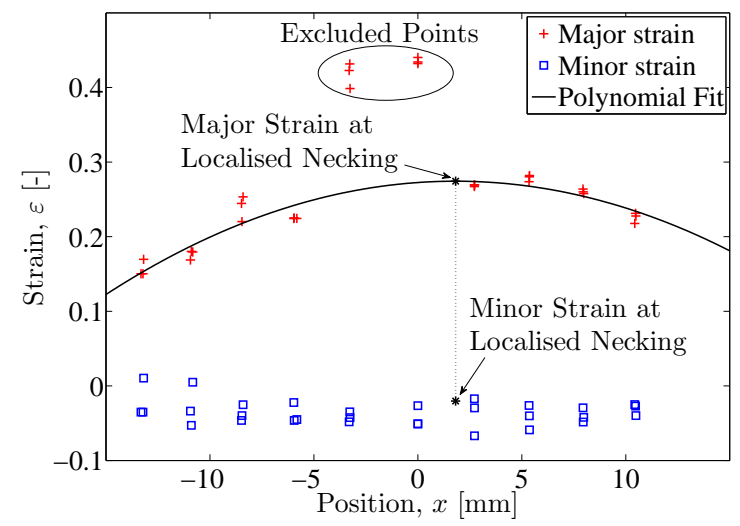

(a)

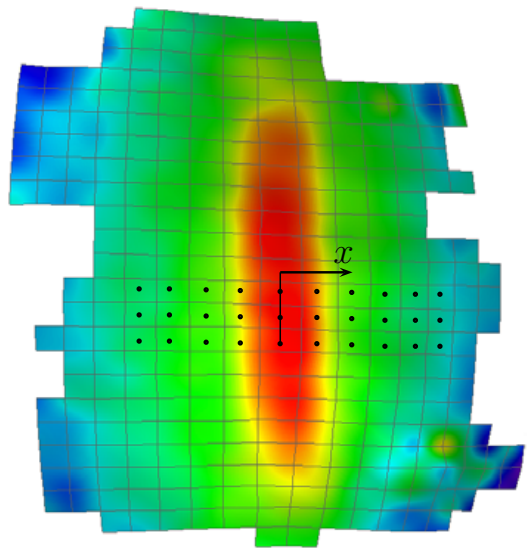

(b)

Figure 7: Illustration of the Bragard et al. (1972) method; (a) polynomial fit to strains and (b) lines of elements across the localisation zone used for strain evaluation.

\section{Constitutive model}

The constitutive model used for the two steels and its parameter calibration are presented in Larsson et al. (2011). A summary of these equations is given in Table 1. It is to be noted that all variables are referred to a co-rotated configuration, see e.g. Belytschko et al. (2000). Henceforth, all constitutive relations will be related to the co-rotated configuration. In Table 1, the equation for the effective stress Yld2003 is given, see Aretz (2005). In its original version, it is derived for a plane stress state, i.e. $\Sigma_{11}^{*}=\Sigma_{11}$ and $\Sigma_{22}^{*}=\Sigma_{22}$, where the 11-direction and 22-direction correspond to the RD and the TD, respectively. However, a regularisation that enables thickness continuity across the element edges has been made here. Thus, the throughthickness stress is included, and $\Sigma_{11}^{*}=\Sigma_{11}-\Sigma_{33}$ and $\Sigma_{22}^{*}=\Sigma_{22}-\Sigma_{33}$ where the 33-direction corresponds to the normal direction (ND) of the sheet. The transversal shear stresses are not included in the effective stress and are only considered in order to achieve stability according to the theory of ReissnerMindlin, see Hughes (2000). The material model is implemented in the FE code LS-DYNA, see Hallquist (2009), and the material parameters of Docol 600DP and Docol 1200M can be found in Table 2 . 
Table 1: Constitutive formulation.

\begin{tabular}{|c|c|}
\hline Stress update: & $\dot{\boldsymbol{\sigma}}=\boldsymbol{C}:\left(\boldsymbol{D}-\boldsymbol{D}^{p}\right)$ \\
\hline Yield function: & $f=\bar{\sigma}(\boldsymbol{\Sigma})-\sigma_{i s o}^{y}\left(\bar{\varepsilon}^{p}\right)$ \\
\hline Associated flow rule: & $\boldsymbol{D}^{p}=\dot{\lambda} \frac{\partial f}{\partial \boldsymbol{\sigma}}$ \\
\hline Reduced stress tensor: & $\Sigma=\sigma-\alpha$ \\
\hline Equivalent plastic strain: & $\begin{array}{l}\bar{\varepsilon}^{p}=\int_{0}^{t} \dot{\bar{\varepsilon}}^{p} \mathrm{~d} t, \quad \dot{\bar{\varepsilon}}^{p}=\frac{\boldsymbol{\Sigma}: \boldsymbol{D}^{p}}{\bar{\sigma}} \\
\sigma_{i s o}^{y}\left(\bar{\varepsilon}^{p}\right)=\left\{\begin{array}{cc}\sigma_{0}+\sum_{i=1}^{2} Q_{R i}\left(1-e^{-C_{R i} \bar{\varepsilon}^{p}}\right) & \bar{\varepsilon}^{p} \leq \varepsilon^{t} \\
A+B\left(\bar{\varepsilon}^{p}\right)^{C} & \bar{\varepsilon}^{p}>\varepsilon^{t}\end{array}\right.\end{array}$ \\
\hline Back stress evolution: & $\dot{\boldsymbol{\alpha}}_{i}=\sum C_{X i}\left(Q_{X i} \frac{\boldsymbol{\Sigma}}{\overline{\bar{\sigma}}}-\boldsymbol{\alpha}_{i}\right) \dot{\bar{\varepsilon}}^{p}$ \\
\hline Equivalent stress: & $\bar{\sigma}(\boldsymbol{\Sigma}) \stackrel{i}{=}\left[\frac{1}{2}\left(\left|\Sigma_{1}^{\prime}\right|^{a}+\left|\Sigma_{2}^{\prime}\right|^{a}+\left|\Sigma_{1}^{\prime \prime}-\Sigma_{2}^{\prime \prime}\right|^{a}\right)\right]^{1 / a}$ \\
\hline & $\left.\begin{array}{c}\Sigma_{1}^{\prime} \\
\Sigma_{2}^{\prime}\end{array}\right\}=\frac{A_{8} \Sigma_{11}^{*}+A_{1} \Sigma_{22}^{*}}{2} \pm \sqrt{\left(\frac{A_{2} \Sigma_{11}^{*}-A_{3} \Sigma_{22}^{*}}{2}\right)^{2}+A_{4}^{2} \Sigma_{12} \Sigma_{21}}$ \\
\hline & $\left.\begin{array}{c}\Sigma_{1}^{\prime \prime} \\
\Sigma_{2}^{\prime \prime}\end{array}\right\}=\frac{\Sigma_{11}^{*}+\Sigma_{22}^{*}}{2} \pm \sqrt{\left(\frac{A_{5} \Sigma_{11}^{*}-A_{6} \Sigma_{22}^{*}}{2}\right)^{2}+A_{7}^{2} \Sigma_{12} \Sigma_{21}}$ \\
\hline
\end{tabular}

\section{Numerical simulation}

FE analyses of the shear, plane strain, and Nakajima experiments were performed. In all simulations, a generalised shell formulation that enables $C^{0}$ continuity of the thickness across the element edges has been used, cf. element type 26 in LS-DYNA, Hallquist (2009). This continuity also reduces spurious strain localisation. However, the introduction of the normal stress also includes transversal shear stresses. The transversal shear stresses are uncoupled to the elasto-plastic constitutive model, but are updated to maintain stability. Selective integration in the shell plane and five integration points through the thickness have been used in all simulations.

\subsection{Simple shear test}

The FE model of the shear test specimen is shown in Figure 8. It consists of about 12500 shell elements, and the characteristic element size in the shear zone is approximately $0.06 \mathrm{~mm}$, see Figure $8(\mathrm{~b})$. It should be noted that the localization zone, which width is about the sheet thickness, contains several elements. A good agreement between the force displacement relations from 
Table 2: Parameter setting for constitutive formulation.

\begin{tabular}{lrr} 
& Docol $600 \mathrm{DP}$ & Docol $1200 \mathrm{M}$ \\
\hline$E[\mathrm{GPa}]$ & 200 & 210 \\
$\nu$ & 0.3 & 0.3 \\
$\varepsilon_{t}[\%]$ & 12.6 & 1.00 \\
$\sigma_{0}[\mathrm{MPa}]$ & 349 & 833 \\
$Q_{R 1}[\mathrm{MPa}]$ & 271 & 20 \\
$C_{R 1}$ & 12 & 357 \\
$Q_{R 2}[\mathrm{MPa}]$ & 35 & 24 \\
$C_{R 2}$ & 91 & 3824 \\
$A[\mathrm{MPa}]$ & 259 & 875 \\
$B[\mathrm{MPa}]$ & 591 & 175 \\
$C$ & 0.28 & 0.96 \\
$Q_{X 1}[\mathrm{MPa}]$ & 0 & 180 \\
$C_{X 1}$ & 0 & 357 \\
$Q_{X 2}[\mathrm{MPa}]$ & 140 & 224 \\
$C_{X 2}$ & 91 & 3824 \\
$a$ & 6.47 & 4.60 \\
$A_{1}$ & 0.95 & 0.88 \\
$A_{2}$ & 1.01 & 0.96 \\
$A_{3}$ & 1.01 & 1.01 \\
$A_{4}$ & 0.96 & 1.01 \\
$A_{5}$ & 1.01 & 0.95 \\
$A_{6}$ & 0.98 & 0.93 \\
$A_{7}$ & 0.93 & 0.95 \\
$A_{8}$ & 0.97 & 1.12 \\
\hline
\end{tabular}

FE simulations and experiments was found, see Figure 9. Since the strain field is better resolved with a denser mesh, the fracture will be influenced by the mesh size. The failure parameters will be FE mesh dependent and it is therefore necessary to consider a length scale when evaluating the fracture parameters. Thus, a nonlocal procedure is preferred. The nonlocal fracture parameters can be constructed in different ways, but most often they are based on a mean value evaluated on a specified region in space, see e.g. PijaudierCabot and Bazant (1987). In this study, the fracture parameters have been 
derived from the shear test FE model data along a line of specified length $(0.2 \mathrm{~mm})$ in the direction of the experimentally obtained fracture surface, see Figure 10(a). This fracture line was found to be approximately $20^{\circ}$ to the loading direction. Simulations of the shear test have been performed for three different element sizes, viz. about $0.18,0.06$ and $0.03 \mathrm{~mm}$. From the FE simulations, the largest value of the fracture parameter at the peak load arises at the edge. As can be seen in Figure 10(b), the evaluated fracture parameter decreases rapidly for the first number of elements, after which it flattens out. For the element sizes of 0.06 and $0.03 \mathrm{~mm}$, the flat apperance occurs after approximately $0.2 \mathrm{~mm}$. For the element size of $0.18 \mathrm{~mm}$, this decrease is somewhat slower. From the force displacement relation, it can be seen that the coarser element size yields a too stiff response, see Figure 10(c). The nonlocal value of the failure parameter has been obtained from

$$
W^{\text {nonlocal }}=\frac{1}{N} \sum_{i=1}^{N} W_{i}
$$

where $N$ is the number of elements along the specified line and $W_{i}$ is the local value of the fracture parameter at each element. As can be seen from Figure 10(c) and Table 3, the nonlocal approach reduces the mesh dependency considerably. In an industrial application the FE mesh must be coarse of efficiency reasons, and the localized zone may completely or partly be contained within one element. An approach to account for a local failure is to use an adaptive FE methodology, i.e. the mesh is adaptively refined to capture the localized failure based on a chosen refinement criterion. Alternatively, failure can be captured by scaling the failure parameters according to element sizes, i.e. the same plastic energy is dissipated at failure when using the different element sizes.

Table 3: Nonloacal fracture parameter.

\begin{tabular}{ccc}
$\begin{array}{c}\text { Element size } \\
l_{e}[\mathrm{~mm}]\end{array}$ & $\begin{array}{c}\text { Fracture parameter } \\
W_{c}[\mathrm{MPa}]\end{array}$ \\
\hline 0.03 & 1815 & 826 \\
0.06 & 1483 & 818 \\
0.18 & 839 & - \\
\hline
\end{tabular}




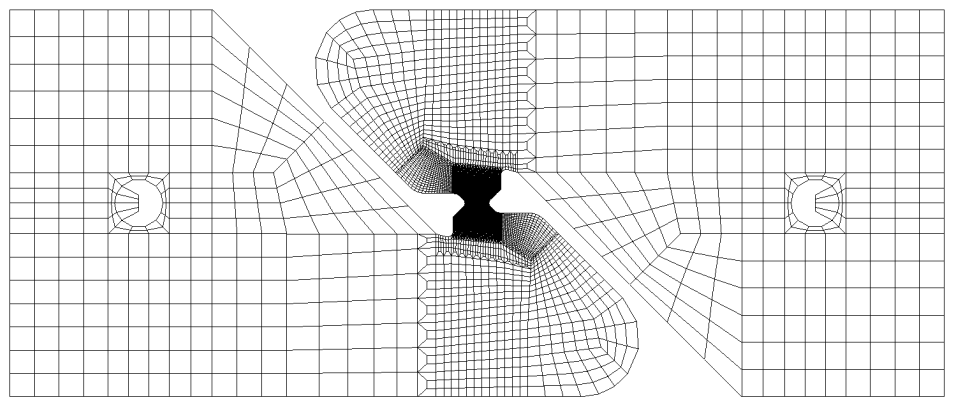

(a)

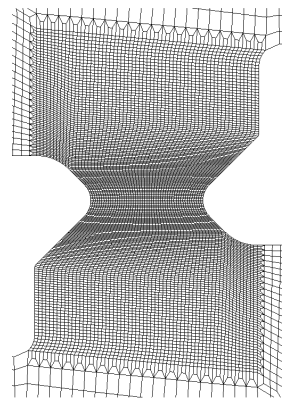

(b)

Figure 8: (a) FE model of the shear test. (b) Details of the mesh in the shear zone.

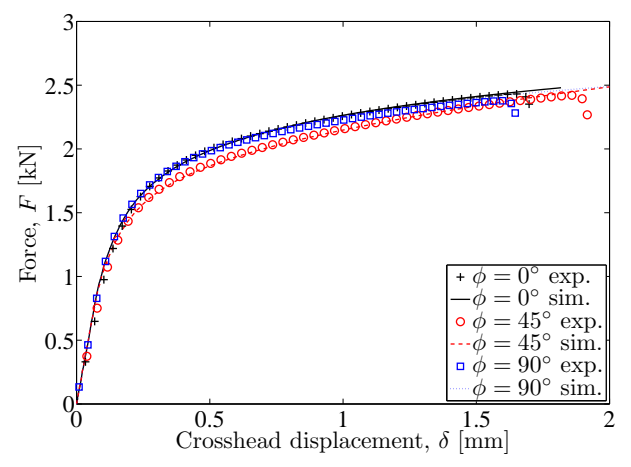

(a)

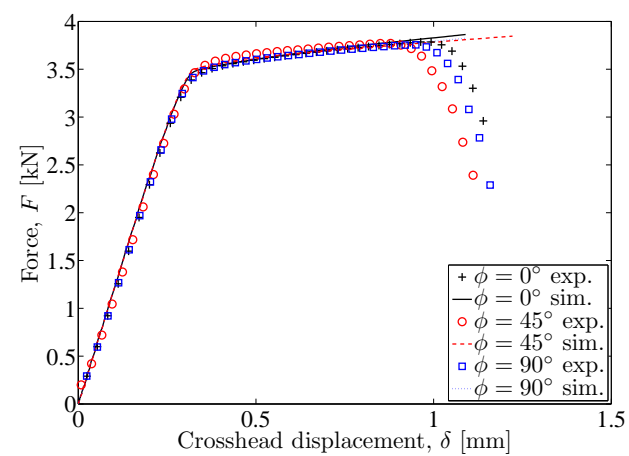

(b)

Figure 9: Simulation and experimental results from the shear tests, where $\phi$ is the angle relative to the rolling direction: (a) Docol 600DP and (b) Docol 1200M.

\subsection{Plane strain test}

The FE model of the plane strain test specimen can be seen in Figure 11. The model consists of about 7900 shell elements, and the element size in the centre of the specimen is approximately $0.2 \mathrm{~mm}$. A good agreement between the force displacement relations from FE simulations and tests was found, see Figure 12. In the case of the plane strain test, different element sizes show approximatly the same result, and no nonlocal evaluation of the fracture parameter is needed. 




(a)

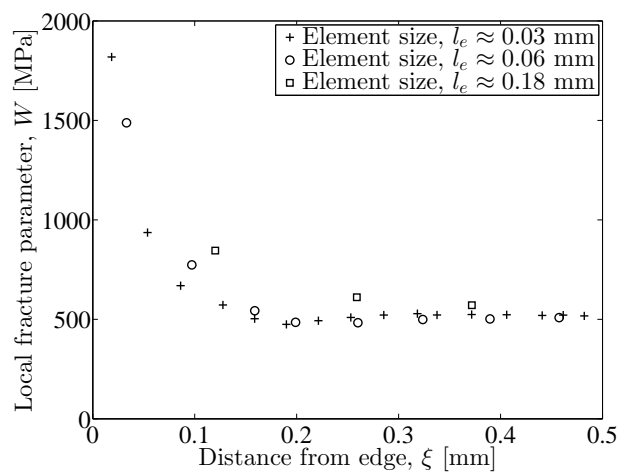

(b)

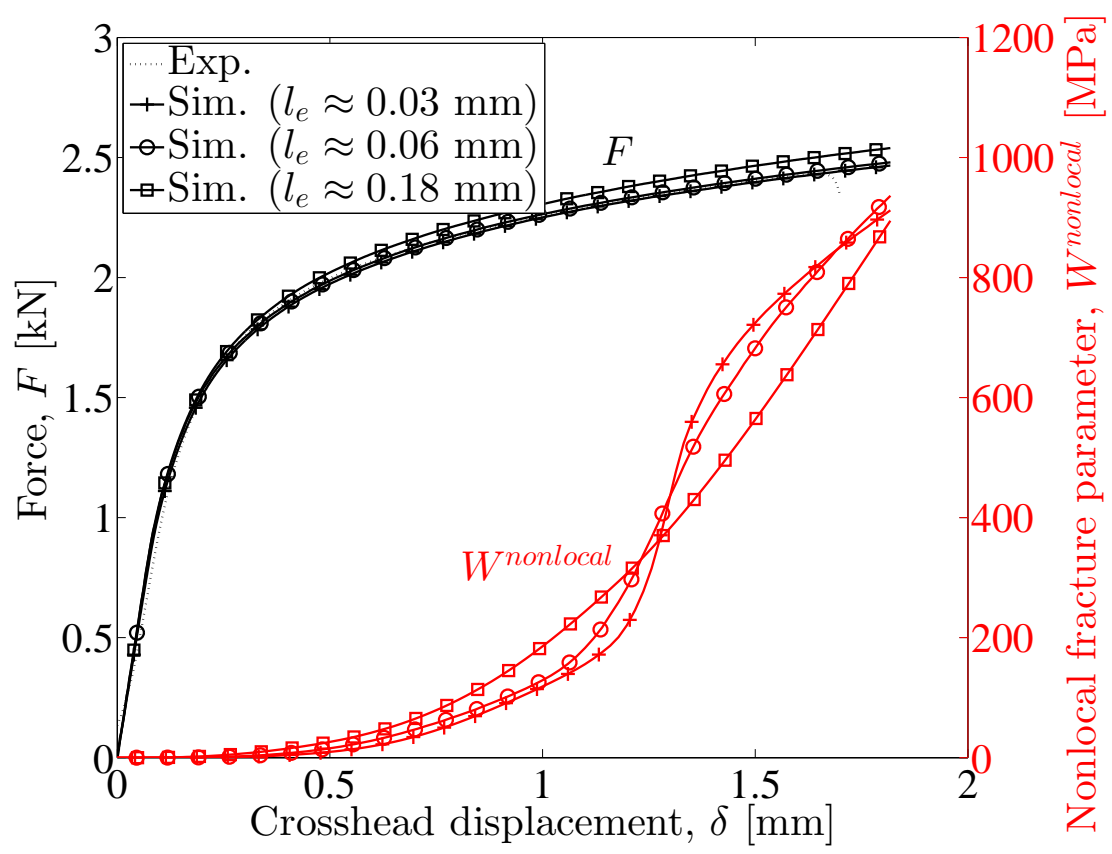

(c)

Figure 10: The line of elements used for the nonlocal failure evaluation (a) line for selected elements and (b) local $W$ values. (c) Force displace relation and growth of nonlocal failure parameter ( $\left.W^{\text {nonlocal }}\right)$, for different element size.

\subsection{Nakajima test}

The characteristic element size in the FE models of the Nakajima specimens was approximately $0.75 \mathrm{~mm}$, i.e. about half the sheet thickness $t \approx$ 




Figure 11: FE model of the plane strain test.

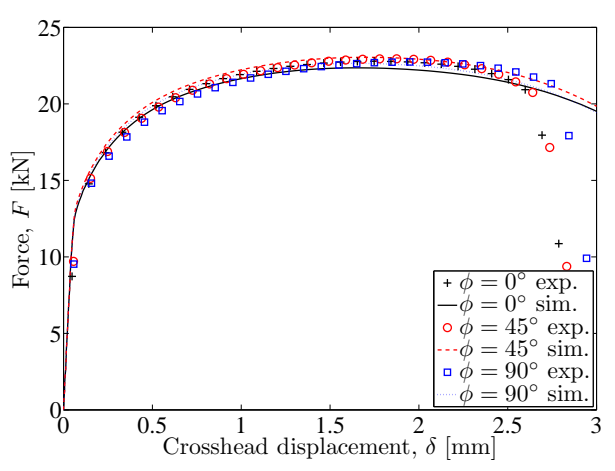

(a)

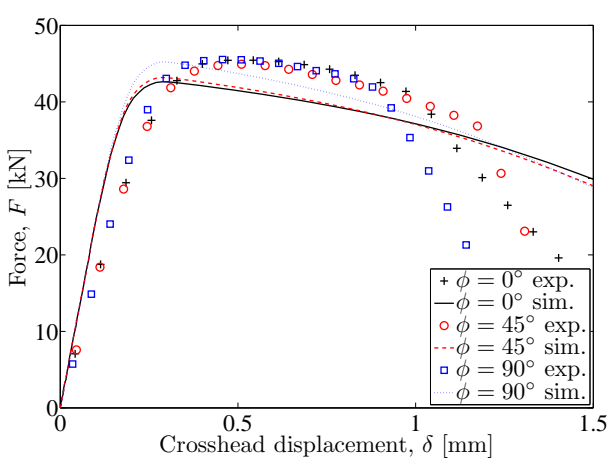

(b)

Figure 12: Simulation and experimental results from the plane strain tests, where $\phi$ is the angle relative to the rolling direction: (a) Docol 600DP and (b) Docol 1200M.

$1.5 \mathrm{~mm}$. Since the Nakajima tests are used for validation of the failure behaviour it is necessary to introduce a minor perturbation of the thickness variation in order to capture the instability correctly. The perturbation was introduced in the same manner as for the element patch, see Section 2.3, 
i.e. independent of the mesh size and with an attempt to obtain a similar thickness variation as observed in the measurements, see Section 3.

\section{Parameter identification}

The models for ductile fracture and through-thickness shear fracture described above relate to different parts of the FLD. Consequently, different experiments are chosen to calibrate the corresponding fracture parameters. For the ductile fracture, the shear test is used to find the $W_{c}$ parameter. The strain path of the shear test is on the second quadrant of the FLD $\left(\varepsilon_{1} \geq 0\right.$, $\varepsilon_{2} \leq 0$ ), and no instability was observed before fracture. For the throughthickness shear fracture the plane strain test is used to find the $\tau_{c}$ parameter. In these tests the fracture surface was found to be inclined through the thickness, which indicates a shear fracture. The calibration of the fracture models is carried out as a post-processing step i.e. only the onset of fracture is detected.

\subsection{Ductile fracture model}

In order to evaluate the fracture criterion according to the CockroftLatham, Equation 3, comparisons of results from the experiments and the $\mathrm{FE}$ simulations were undertaken. In order to evaluate the fracture criterion, the evolution of the nonlocal fracture parameter, $W^{\text {nonlocal }}$, from the FE simulation is evaluated as a function of the crosshead displacement. In the shear test the maximum applied load will occur close to the complete material separation $(F=0)$. Thus fracture is determined to take place at the maximum applied load and the critical value, $W_{c}$, is found at the corresponding crosshead displacement. Since the ductile fracture model only has one parameter, one single experiment and $\mathrm{FE}$ simulation is enough to determine $W_{c}$. However, in this study several experiments were performed in three material directions and a range of the fracture parameter, $W_{c}$, was obtained. It is to be noted that the FE simulation is deterministic and the distribution of the fracture parameter is only due to the scatter of the experimental results. The evaluation procedures of the parameter $W_{c}$ for Docol 600DP and Docol 1200M are shown in Figure 13, where the evolution of the force-crosshead displacements and the fracture parameter, $W^{\text {nonlocal }}$, are compared for one representative experiment on each material. The maximum, minimum and mean values of $W_{c}$, and the crosshead displacement 
at fracture can be found in Tables 4 and 5 for each material direction of Docol 600DP and Docol 1200M, respectively.

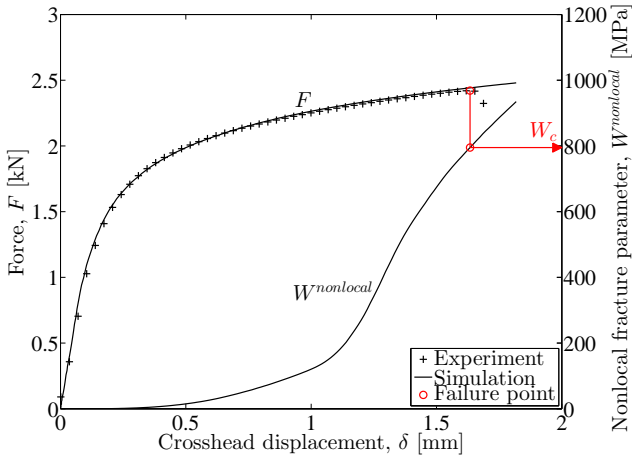

(a)

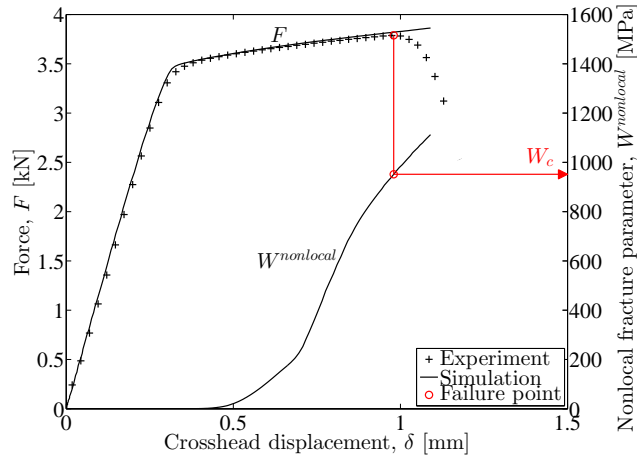

(b)

Figure 13: Evaluation of the ductile fracture parameter, $W_{c}$, from the shear test in the rolling direction (RD): (a) Docol 600DP and (b) Docol 1200M.

Table 4: Maximum, minimum and mean for the failure parameter $W_{c}$ for Docol 600DP, derived from the nonlocal value of $W$ from the shear test in different material directions.

Fracture parameter Displacement

\begin{tabular}{lcccccc} 
& \multicolumn{3}{c}{$W_{c}[\mathrm{MPa}]$} & \multicolumn{3}{c}{$\delta[\mathrm{mm}]$} \\
Direction & Max & Min & Mean & Max & Min & Mean \\
\hline RD & 839 & 776 & 804 & 1.69 & 1.61 & 1.64 \\
DD & 636 & 618 & 628 & 1.90 & 1.86 & 1.88 \\
TD & 821 & 773 & 794 & 1.65 & 1.60 & 1.62 \\
\hline Total & 839 & 618 & 742 & 1.90 & 1.60 & 1.72 \\
\hline
\end{tabular}

\subsection{Through-thickness shear fracture model}

In order to evaluate the through-thickness shear fracture according to the Bressan-Williams criterion, Equation 6, results from the experiments and FE simulations of plane strain tests were compared. The procedure to calibrate this fracture model is similar to the one described in the previous section. A comparison between the force-crosshead displacement relation 
Table 5: Maximum, minimum and mean for the failure parameter $W_{c}$ for Docol 1200M, derived from the nonlocal value of $W$ from the shear test in different material directions.

\begin{tabular}{lcccccc} 
& \multicolumn{2}{c}{ Fracture parameter } & \multicolumn{3}{c}{ Displacement } \\
& \multicolumn{3}{c}{$W_{c}[\mathrm{MPa}]$} & \multicolumn{3}{c}{$\delta[\mathrm{mm}]$} \\
Direction & Max & Min & Mean & Max & Min & Mean \\
\hline RD & 985 & 926 & 947 & 1.00 & 0.96 & 0.98 \\
DD & 783 & 479 & 661 & 0.87 & 0.78 & 0.83 \\
TD & 910 & 852 & 877 & 0.95 & 0.92 & 0.93 \\
\hline Total & 985 & 479 & 828 & 1.00 & 0.78 & 0.91 \\
\hline
\end{tabular}

from the experiments and corresponding FE simulation results was carried out. Fracture was here assumed to initiate when a significant drop in the applied load was observed, see Figure 14. However, this drop in the applied load occurs after the point of maximum load, which fact indicates that an instability has arisen prior to the shear fracture. The critical value, $\tau_{c}$, of the through thickness shear stress can therefore be regarded as the upper limit of the fracture. The maximum, minimum, and mean values of $\tau_{c}$ and the crosshead displacement at fracture can for each direction be found in Tables 6 and 7 for Docol 600DP and Docol 1200M, respectively.

Table 6: Maximum, minimum, and mean for the failure parameter $\tau_{c}$ for Docol 600DP, derived from the plane strain test in different material directions.

\begin{tabular}{lcccccc} 
& \multicolumn{2}{c}{ Fracture parameter } & \multicolumn{3}{c}{ Displacement } \\
& \multicolumn{2}{c}{$\tau_{c}[\mathrm{MPa}]$} & \multicolumn{3}{c}{$\delta[\mathrm{mm}]$} \\
Direction & Max & Min & Mean & Max & Min & Mean \\
\hline RD & 549 & 513 & 530 & 3.00 & 2.64 & 2.81 \\
DD & 516 & 511 & 514 & 2.73 & 2.68 & 2.7 \\
TD & 536 & 513 & 525 & 2.81 & 2.58 & 2.7 \\
\hline Total & 549 & 511 & 524 & 3.00 & 2.58 & 2.74 \\
\hline
\end{tabular}


Table 7: Maximum, minimum, and mean for the failure parameter $\tau_{c}$ for Docol 1200M, derived from the plane strain test in different material directions.

Fracture parameter Displacement

$$
\tau_{c}[\mathrm{MPa}] \quad \delta[\mathrm{mm}]
$$

\begin{tabular}{lcccccc} 
Direction & Max & Min & Mean & Max & Min & Mean \\
\hline RD & 773 & 765 & 770 & 1.05 & 0.96 & 1.02 \\
DD & 777 & 756 & 764 & 1.19 & 0.97 & 1.06 \\
TD & 797 & 776 & 786 & 0.93 & 0.68 & 0.80 \\
\hline Total & 797 & 756 & 774 & 1.19 & 0.68 & 0.95 \\
\hline
\end{tabular}

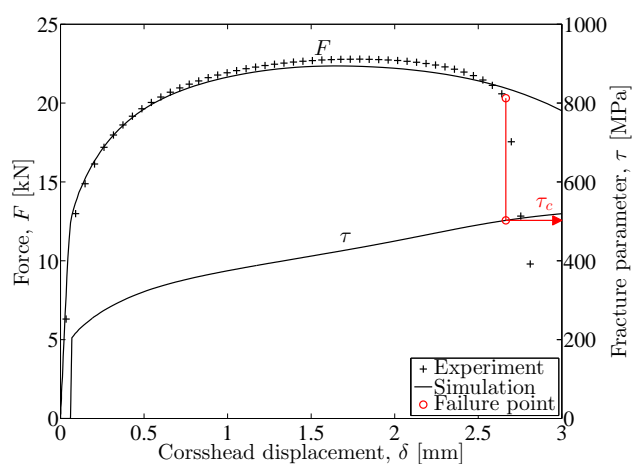

(a)

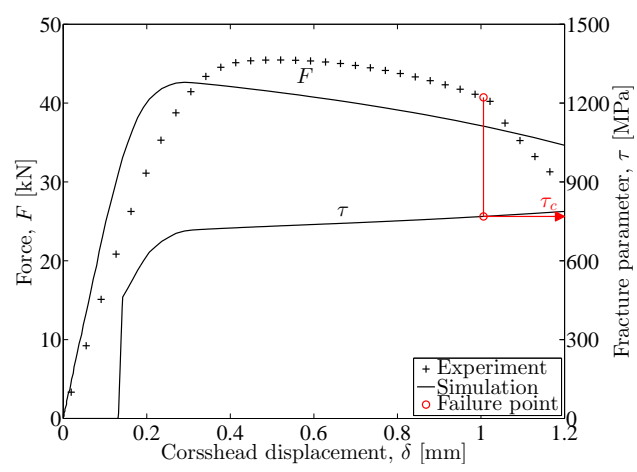

(b)

Figure 14: Evaluation of the shear fracture parameter, $\tau_{c}$, from plane deformation test of material in the rolling direction: (a) Docol 600DP and (b) Docol 1200M.

\section{Results and Discussion}

One drawback with the conventional FLC is that it depends on the loading path, which is generally proportional in its experimental determination, see Hosford and Cadell (1993). The objective of the proposed fracture models is that they should be valid for arbitrary loading paths. Thus, their calibration should be made by FE simulations and results from simple mechanical experiments. In this study, the performance of the fracture models is validated on the Nakajima test, which is generally used for constructing experimental FLCs. 


\subsection{Ductile fracture}

In this work, the ductile fracture is described by the Cockroft-Latham model, which despite its simple form contains information both about the stress triaxiality and the Lode angle, see Equation 4 . The critical value, $W_{c}$, of the model has been derived from the in-plane shear test. In this test, the initial deformation is almost in pure in-plane shear, but eventually it approaches a uniaxial tensile deformation. The sign of the in-plane shear stress component, $\sigma_{12}$, does not influence the magnitude of the equivalent stress, and the same numerical stress strain response is obtained for an inplane shear stress state in the RD as well as in the TD. The differences between the force displacement responses of the shear tests in the RD and the TD are minor. As a consequence, only minor deviations between the $W_{c}$ values are noted, between the RD and the TD, both for Docol 600DP and Docol $1200 \mathrm{M}$, see Tables 4 and 5. In the DD, a lower value for $W_{c}$ is obtained for both materials. For Docol 600DP, the lower value of $W_{c}$ is obtained despite that the deformation at maximum load is larger in the DD. It can be observed from Figure 9(a) that the force displacement response of the specimen in the DD is below the responses in the RD and the TD. In pure in-plane shear, the largest principal stress expressed as a function of equivalent plastic strain, $\sigma_{1}\left(\bar{\varepsilon}^{p}\right)$, in the DD is below the corresponding curves in the RD and the TD. Therefore, a lower value of $W_{c}$ is obtained in the DD compared to the RD and the TD, and since the Cockroft-Latham model describes an isotropic behaviour, this anisotropy cannot be captured. For Docol $1200 \mathrm{M}$, only minor differences in the force displacement responses are noticed for the different directions, see Figure 9(b). In fact, the relation for the largest principal stress, $\sigma_{1}\left(\bar{\varepsilon}^{p}\right)$, in pure in-plane shear in the DD, is slightly above the corresponding curves in the RD and the TD. However, since the maximum load occurs at a smaller displacement in the DD compared to the $\mathrm{RD}$ and the TD, a lower value of $W_{c}$ is obtained. In order to capture the variation in $W_{c}$ between the $\mathrm{RD}$, the TD and the $\mathrm{DD}$, an anisotropic fracture model is needed.

\subsection{Shear fracture}

A modified Bressan-Williams shear fracture model has also been investigated in this work. The critical value, $\tau_{c}$, is obtained from FE simulations of the plane strain tests. Fracture is here assumed to occur at a significant load drop. However, it should be noted that the load drop occurs at a deformation beyond maximum load, which indicates that an instability has occurred prior 
to fracture. Thus, the obtained critical value, $\tau_{c}$, depends on how well the material model predicts the stress state beyond maximum load. Since the fracture model depends on the stress state and the ratio between the in-plane principal strains, the model will be affected by the strain hardening of the material. Docol 600DP displays a significant strain hardening in the range of $0 \leq \bar{\varepsilon}^{p} \leq 0.7$, and as a consequence a large variation of $\tau_{c}$ occurs in the different material directions, see Table 6 . However, the variation of the FLC in the different material directions is minor, as can be seen in Figure 15. Docol 1200M, on the other hand, displays only small strain hardening for strains larger than a few percent, which implies that a large variation in strain yields a small variation in stress. Consequently, there is only a small variation in $\tau_{c}$ values for Docol $1200 \mathrm{M}$, see Table 7. However, the deviations in the FLC between the different material directions are large, see Figure 16. Hence, an anisotropic fracture model would be needed to capture this phenomenon.

\subsection{Instability failure}

The plastic instability has in this work been predicted directly from the constitutive law and the FE model. The strain hardening and the shape of the yield surface will affect the instability significantly. Other parameters, e.g. the FE formulation and the element mesh density, will also affect the local instability. A dense mesh is needed to capture the localisation, which is of the same size as the sheet thickness. The size of the local imperfection used to trigger instability in the FE simulation will also affect the instability, and a smaller imperfection will delay the onset of instability. In this work, the thicknesses of the shell elements in the mesh have been chosen to match the thickness imperfections measured on the physical components, see Section 5.3. It is to be noted that the local instability in the Nakajima test also will be influenced by other effects, e.g. friction and the radius of the punch.

\subsection{Nakajima experiments}

Results from the experiments and simulations of the Nakajima tests are shown in Figures 17 to 22. Simulations with and without activated fracture models have been studied. In the case of simulations without activated fracture conditions, the growth of $W$ and $\tau$ can be monitored. The results are also presented in FLDs, where the failure strains are shown in the RD and the TD, respectively, see Figures 15 and 16. 


\subsubsection{Docol 600DP}

Instability seems to be the reason for failure in the case of Nakajima test specimens with a waist of $60 \mathrm{~mm}$, in which the strain paths are in the negative quadrant $\left(\varepsilon_{1}>0, \varepsilon_{2}<0\right)$ of the FLD. From the simulations without any activated fracture models, the point of maximum load, in both material directions, occurs at a deformation which is close to the one observed at fracture in the experiments, see Figures $17(\mathrm{a})$ and 17(b). Since the local instability is governed by the constitutive law and the FE mesh, an anisotropic behaviour may be predicted. However, Docol 600DP shows only minor anisotropy and only a small variation between the material directions is noticed. At local instability the deformation is localised to a small region where the fracture parameters will grow rapidly. This phenomenon can also be observed from the simulations since $W$ and $\tau$ are rapidly increasing near the point of maximum load. This effect is most pronounced for the $W$ value, since it depends on the maximum principal stress, $\sigma_{1}$, and the equivalent plastic strain, $\bar{\varepsilon}^{p}$, which both increase rapidly at localisation.

In the case of Nakajima specimens with a waist of $80 \mathrm{~mm}$ failure is also caused by instability. These specimens are loaded in a close to a plane strain condition. The point of maximum load occurs at a larger deformation in the simulation compared to the experiments, see Figures $17(\mathrm{c})$ and $17(\mathrm{~d})$. However, from the FLD in Figure 15, it is noted that the local instability occurs at larger strains for specimens in the RD and at smaller strains for specimens in the TD. It is to be noted that the FLC is derived from FE analysis of a plane specimen, hence, the punch curvature and friction effects in the Nakajima test are disregarded.

Even for the specimens with a waist of $100 \mathrm{~mm}$ local instability is the driving phenomenon causing failure. The strain paths for these specimens are slightly towards the positive quadrant $\left(\varepsilon_{1}>0, \varepsilon_{2}>0\right)$ of the FLD, see Figure 15, and a minimum point of the FLC is observed. However, the minimum point is not captured by the instability in the simulations, in which case a minimum occurs at plane strain. The minimum point at plane strain is probably a consequence of that the FLC is derived from FE analysis of a plane specimen, which not includes the punch curvature and friction effects in the Nakajima tests.

In the case of specimens with a waist of $120 \mathrm{~mm}$ the fracture in the simulation is caused by a local instability, which is found to occur at larger deformation in the simulation compared to the experiments, see Figures 18(c) 
and $18(\mathrm{~d})$. The fracture surface in the middle of the specimens is inclined through the thickness, which indicates a shear fracture. Also for specimens with a waist of $130 \mathrm{~mm}$ the fracture is predicted to occur at a larger displacement compared to experiments, see Figures 19(a) and 19(b). Even in this case the fracture surface in the middle of the test specimens is inclined. In the case of specimens with a waist of $130 \mathrm{~mm}$ no local instability is observed neither in the simulation results nor in the experiments. The model for predicting the shear fracture has been calibrated using plane strain specimens, which show a maximum in the force displacement response prior to the point used for calibration. Obviously, the prediction of the shear fracture needs improvement in its modelling or calibration. The change in fracture mechanism from ductile to through the thickness shear fracture in the vicinity of plane strain tension in the positive quadrant of the FLD has been reported for high strength steels, e.g. Gruben et al. (2011).

In the case of specimens with a waist of $140 \mathrm{~mm}$ and also the circular specimens the loading is almost a balanced biaxial loading. For these tests the fracture is found to be initiated by a ductile fracture and a good correlation between the simulations and experiments has been achieved, both in the force displacement relations, see Figures 19(c) through 19(e), and in the FLD, see Figure 15.

\subsubsection{Docol $1200 M$}

In the case of Docol 1200M specimens, with a waist between 60 to $100 \mathrm{~mm}$, loaded in an almost plane strain condition or slightly into the positive FLD quadrant, local instability is the reason for failure. For specimens with a waist of 60 and $80 \mathrm{~mm}$ the instability is predicted to occur at smaller displacements than those in the experiments, see Figure 20. For specimens with a waist of $100 \mathrm{~mm}$ there is a large variation in the experimental results, most noticed for the specimens in the RD, see Figure 21(a), but also for specimens in the TD, see Figure 21(b). In the FE simulations it has been observed that a small variation in the friction between the punch and the specimen will cause a large variation in the displacement at maximum load. In this work, the same friction coefficient has been used for both materials and for all specimen geometries. It can thus be argued that the friction should have been modelled differently.

In the case of specimens with a waist of 120 and $130 \mathrm{~mm}$ the loading paths are in the positive quadrant of the FLD. For these tests the prediction of the fracture is poor since the specimens fail after a local instability, which 
was not observed in the tests, see Figures 21(c), 21(d), 22(a) and 22(b). Thus, the reason for the poor prediction in the Docol $1200 \mathrm{M}$ case seems to be caused by the shear fracture model, as in the Docol 600DP case.

In the case of specimens with a waist of $140 \mathrm{~mm}$ and the circular specimens a ductile fracture occurs, which also is predicted in the FE simulations. The fracture is predicted to occur at a larger displacement than what was observed in the experiments, but still before the instability occurs, i.e. before there is a rapid growth in $W$ and $\tau$. Since there is a large scatter in the displacements at fracture for the test used for calibration, see Table 5, there will also be a pronounced scatter in the evaluated $W_{c}$ values. The fracture parameters have here been chosen as the maximum derived value. Alternatively by choosing the minimum value the prediction shows a premature fracture. Consequently, the scatter in the $W_{c}$ values will also be reflected in the Nakajima test results.

\section{Conclusions}

A major objective of the proposed fracture models is their validity for arbitrary load paths. However, at this stage the failure models have only been validated for linear strain paths. The calibration should be made on results from simple mechanical tests and FE simulations. The simulations of the Nakajima tests used for validation predicts the experimental failures well for most specimen geometries. However, in the case of specimens with a waist of 120 and $130 \mathrm{~mm}$, and for both the investigated materials, the Bressan-Williams fracture model fails to predict the observed shear fracture within acceptable tolerances. For several of the specimens it is hard to identify whether the fracture was initiated due to a prior instability or not. In the plane strain test a thickness localisation is observed before fracture, both in the experiments and in the FE simulations. Thus, the fracture parameters, which were calibrated from these experiments, depend on how well the deformation is captured in the localisation zone. The strain path of the plane strain specimen is located slightly in the negative quadrant of the FLD and the strain paths of the Nakajima specimens with a waist of 120 and $130 \mathrm{~mm}$ are in the positive regime. Thus, the poor prediction of the fracture in these cases can either be explained by the fact that the model cannot capture a through thickness shear fracture under these loading conditions or the fact that the plane strain test should not be used for calibration, since a through thickness instability appears before the fracture. Since most of the Naka- 
jima tests and the corresponding FE simulations show an instability before fracture, the prediction of this instability is of significant importance, and thus the accuracy of the constitutive model. In addition, the FE element formulation and mesh size may affect the obtained results to a considerable extent. Finally, we conclude that:

- Ductile fracture is well predicted by the Cockroft-Latham model. However, there is a large scatter in the experimental results, and thus also in the fracture parameter. Hence a statistical procedure may be needed.

- Failure due to a prior instability is predicted well by the constitutive relations and the FE models.

- Shear fracture was not predicted with a satisfying result by the BressanWilliams model, and further studies are needed to improve these predictions.

- The failure parameters need to be scaled when a coarse FE mesh is used such that the dissipated failure energy is preserved.

\section{Acknowledgement}

The work presented in this paper has been carried out with financial support from the SSF ProViking project "SuperLight Steel Structures". 


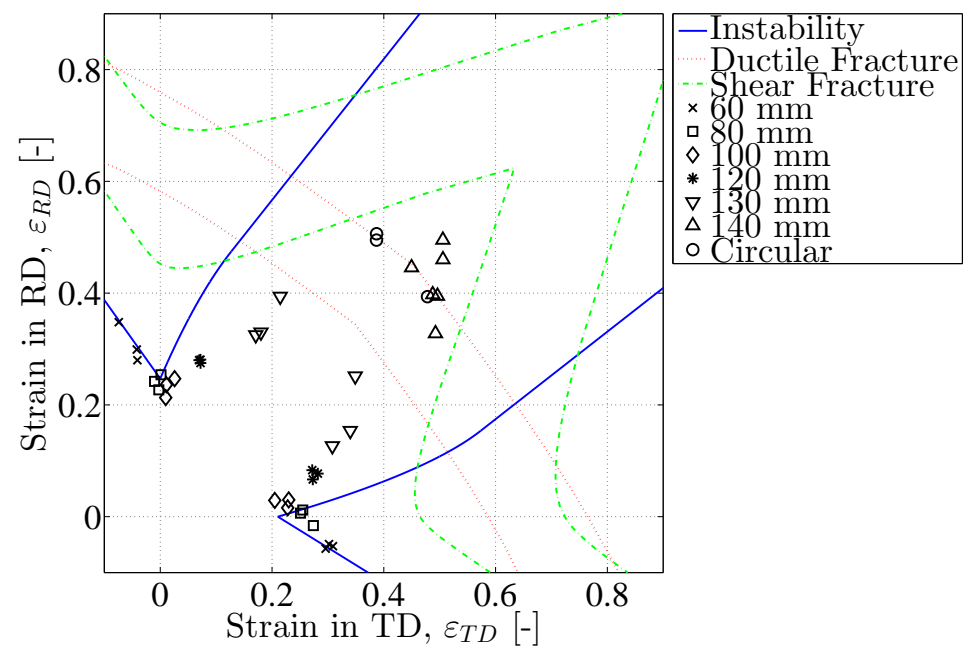

Figure 15: Strain measurements from the Nakajima tests plotted together with the numerical evaluated FLC for Docol 600DP. The two lines for ductile and shear fracture represent the max and min values found for the fracture models in Tables 4 and 6, respectively.

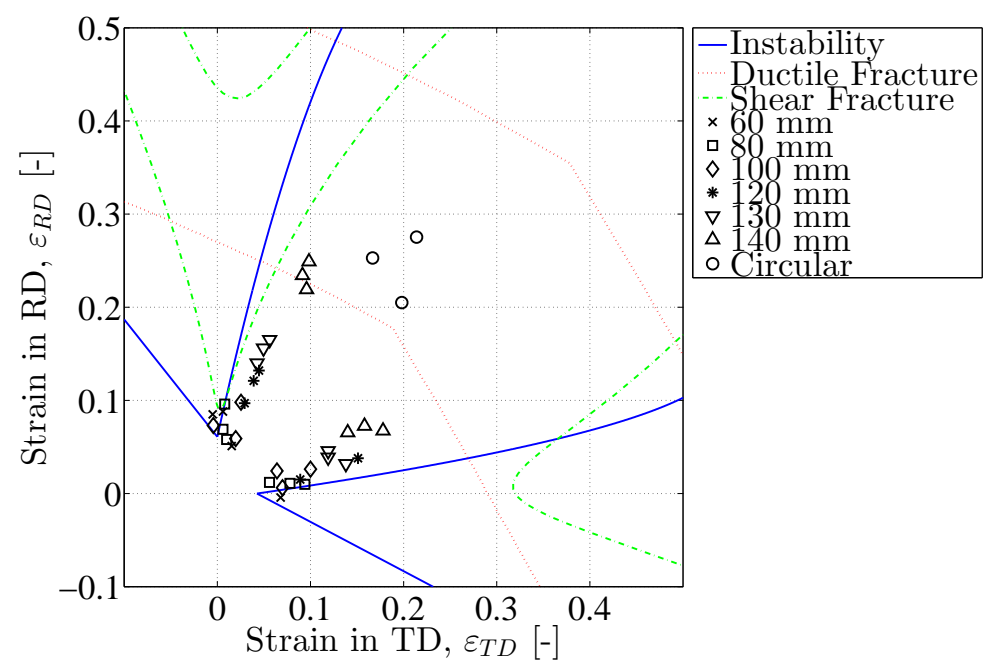

Figure 16: Strain measurements from the Nakajima tests plotted together with the numerical evaluated FLC for Docol 1200M. The two lines for ductile and shear fracture represent the max and min values found for the fracture models in Tables 5 and 7 , respectively. 


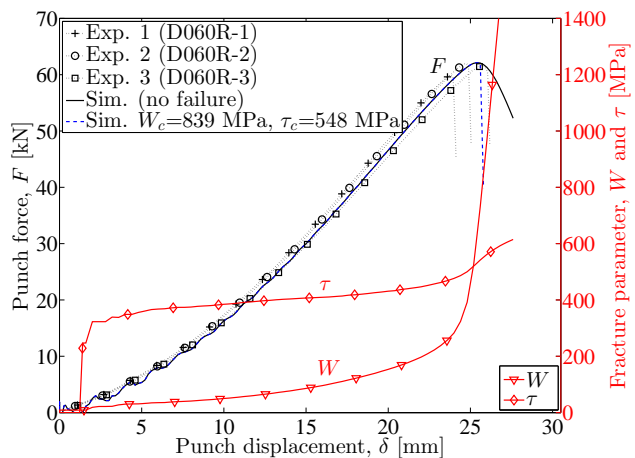

(a)

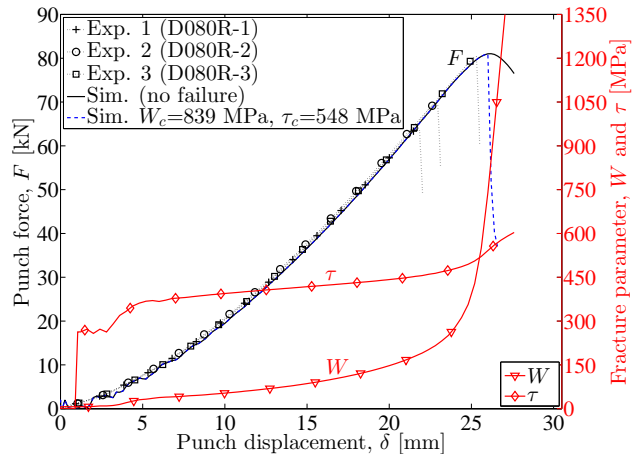

(c)

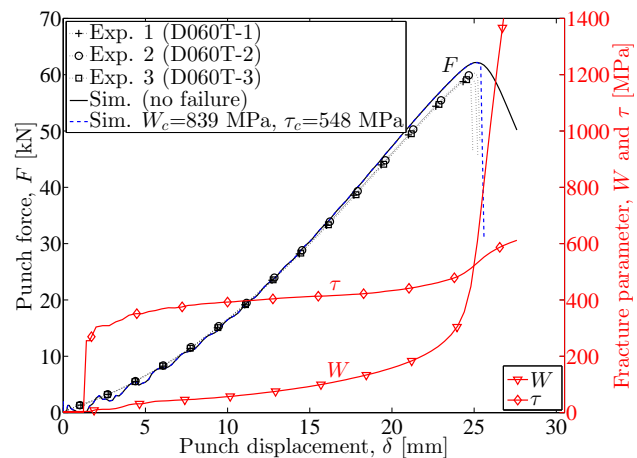

(b)

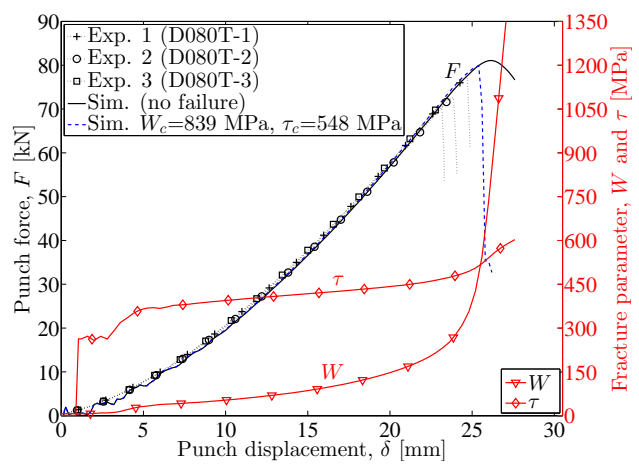

(d)

Figure 17: Results from experiments and FE simulations of the Nakajima tests for Docol $600 D P$ (a) $60 \mathrm{~mm}$ waist in $R D$, (b) $60 \mathrm{~mm}$ waist in $\mathrm{TD}$, (c) $80 \mathrm{~mm}$ waist in $R D$ and (d) $80 \mathrm{~mm}$ waist in $T D$. 


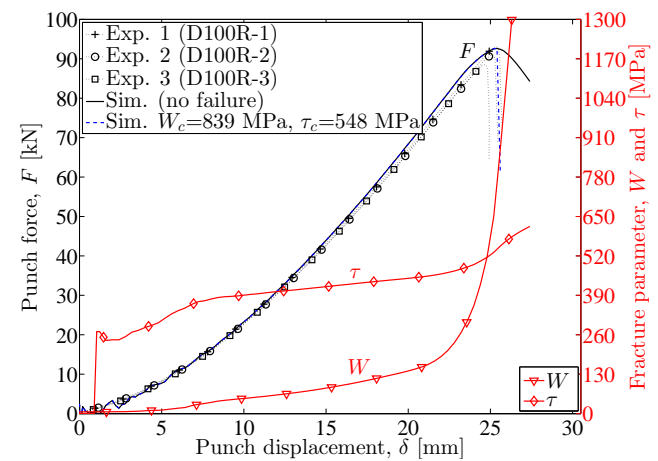

(a)

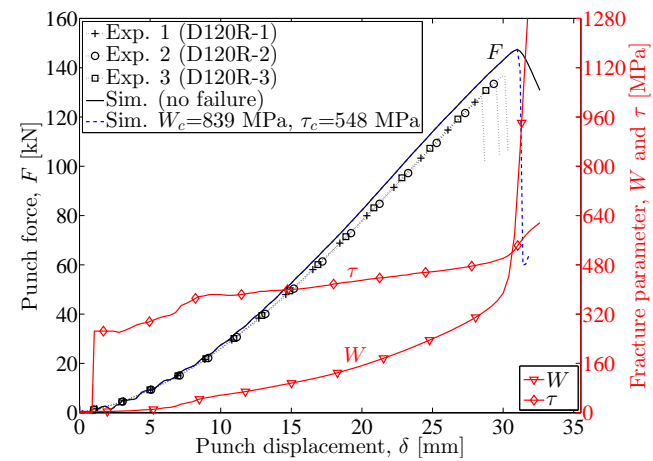

(c)

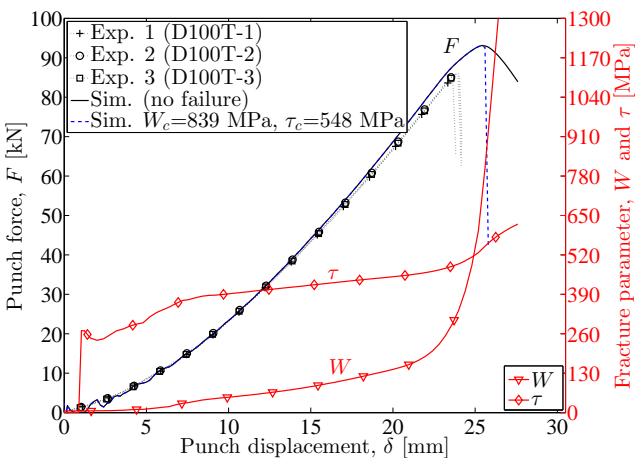

(b)

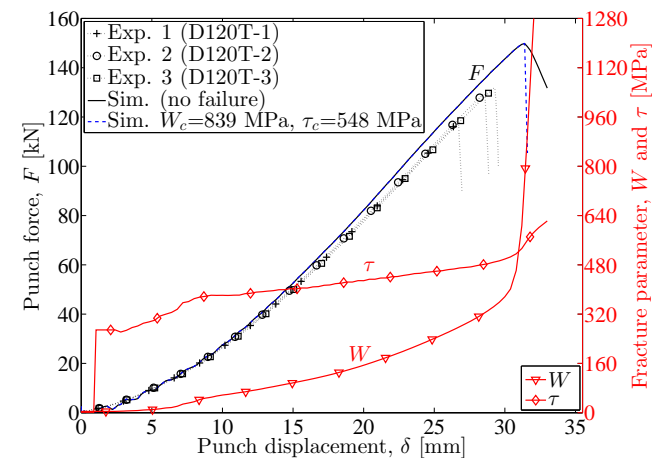

(d)

Figure 18: Results from experiments and FE simulations of the Nakajima tests for Docol 600DP (a) $100 \mathrm{~mm}$ waist in RD, (b) $100 \mathrm{~mm}$ waist in TD, (c) $120 \mathrm{~mm}$ waist in RD and (d) $120 \mathrm{~mm}$ waist in $T D$. 


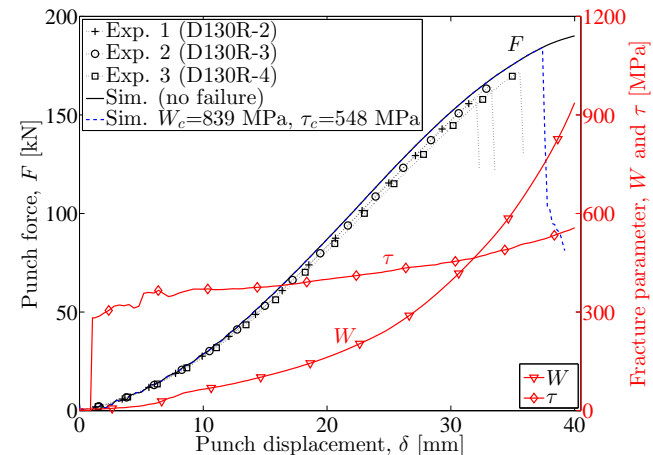

(a)

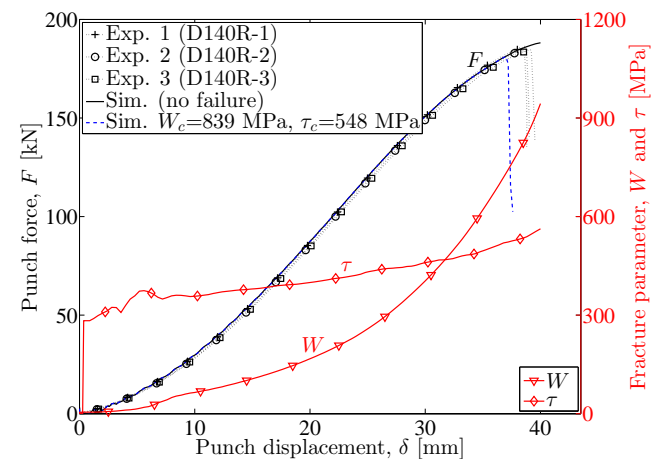

(c)

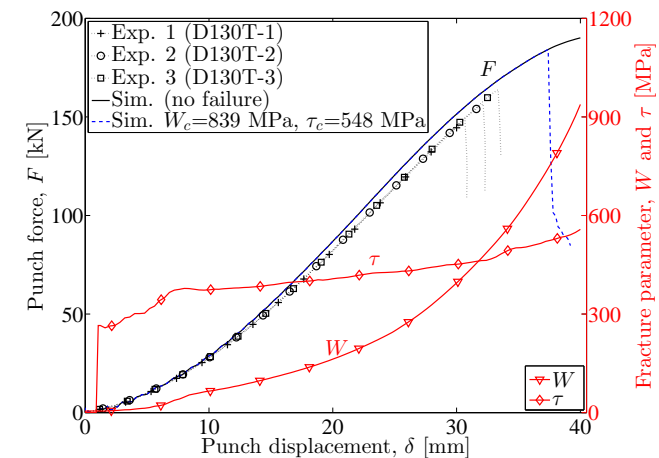

(b)

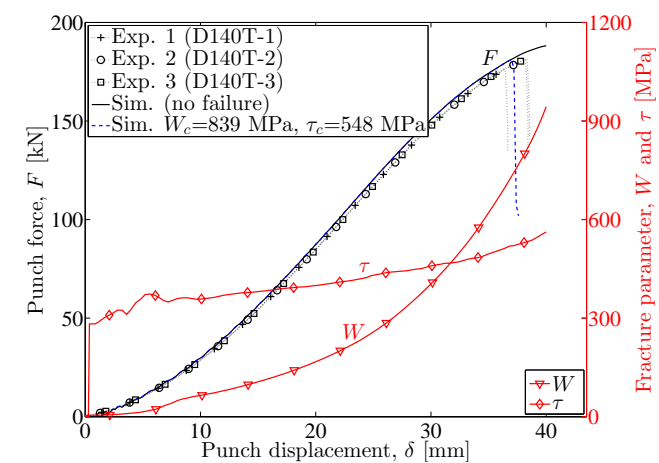

(d)

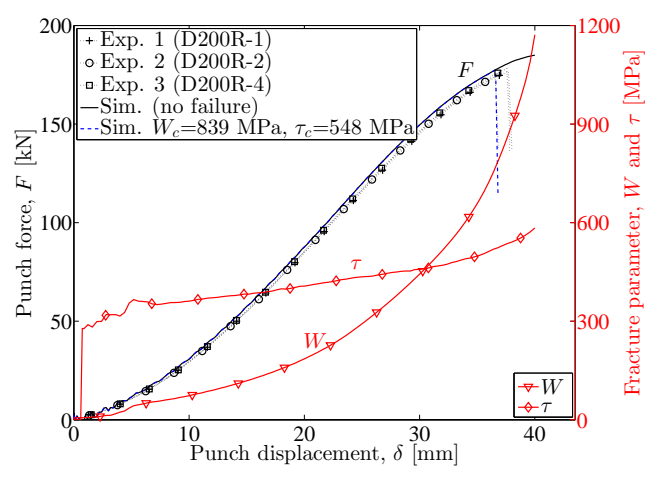

(e)

Figure 19: Results from experiments and FE simulations of the Nakajima tests for Docol 600DP (a) $130 \mathrm{~mm}$ waist in RD, (b) $130 \mathrm{~mm}$ waist in $T D$, (c) $140 \mathrm{~mm}$ waist in $R D$, (d) $130 \mathrm{~mm}$ waist in $T D$ and (e) circular. 


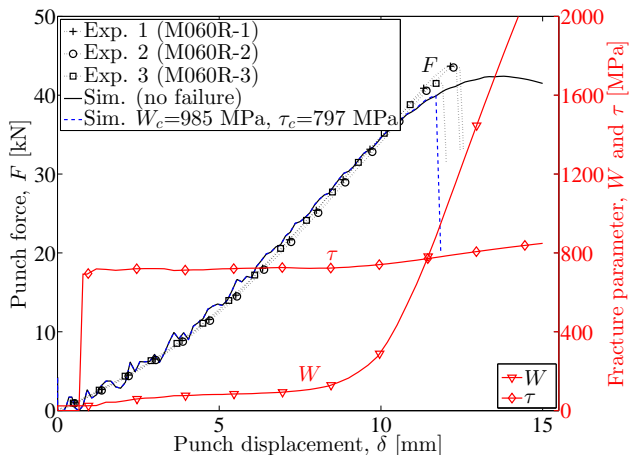

(a)

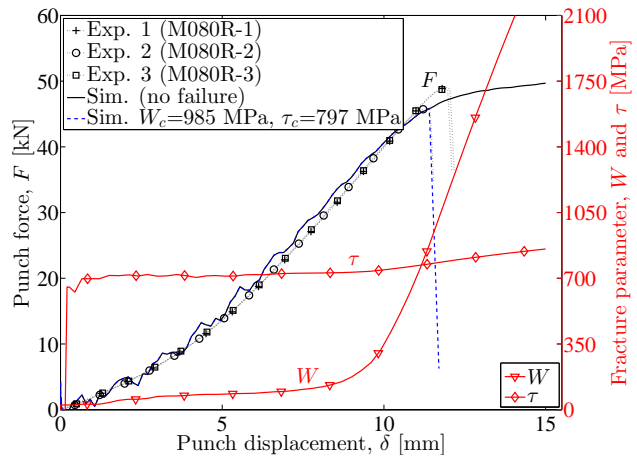

(c)

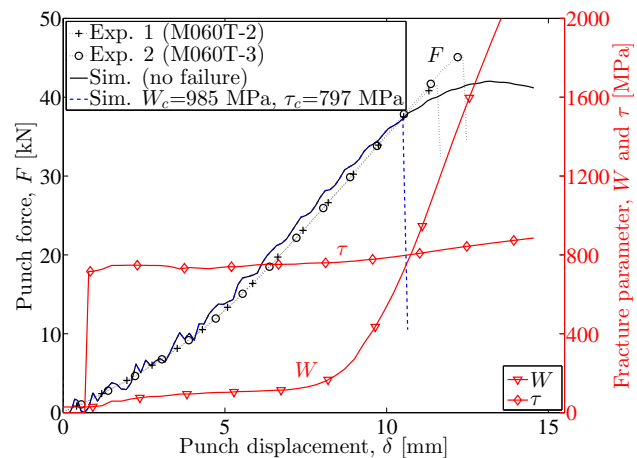

(b)

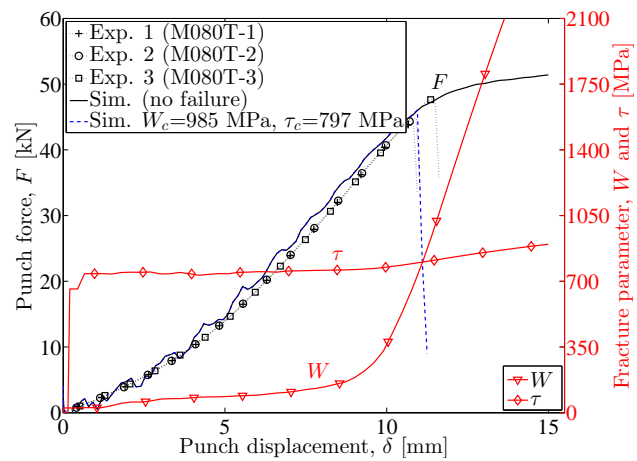

(d)

Figure 20: Results from experiments and FE simulations of the Nakajima tests for Docol $1200 M$ (a) $60 \mathrm{~mm}$ waist in $R D$, (b) $60 \mathrm{~mm}$ waist in $\mathrm{TD}$, (c) $80 \mathrm{~mm}$ waist in $R D$ and (d) $80 \mathrm{~mm}$ waist in $T D$. 




(a)

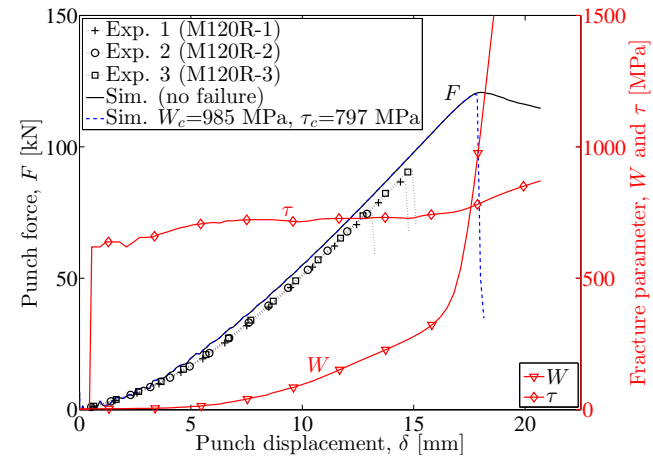

(c)

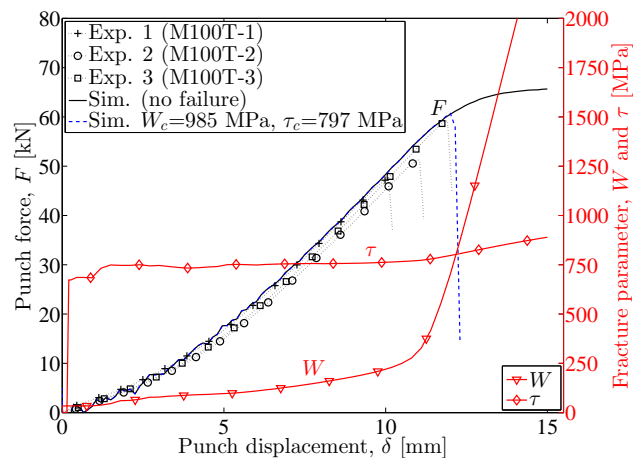

(b)

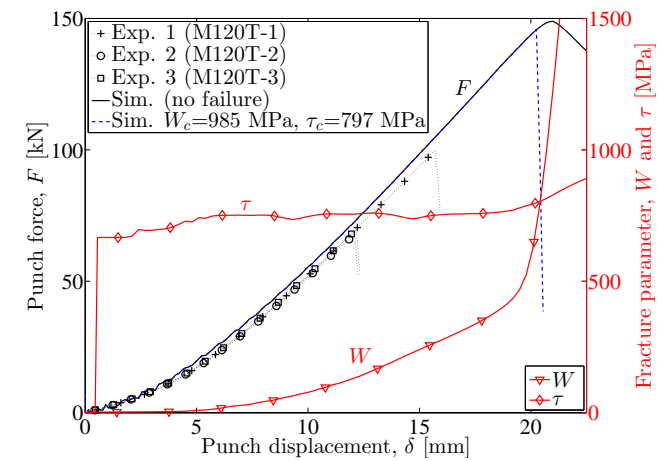

(d)

Figure 21: Results from experiments and FE simulations of the Nakajima tests for Docol $1200 M$ (a) $100 \mathrm{~mm}$ waist in RD, (b) $100 \mathrm{~mm}$ waist in $T D$, (c) $120 \mathrm{~mm}$ waist in $R D$ and (d) $120 \mathrm{~mm}$ waist in $\mathrm{TD}$. 


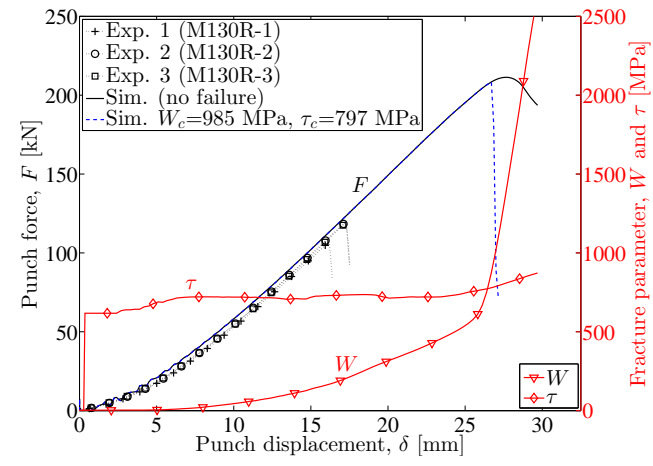

(a)

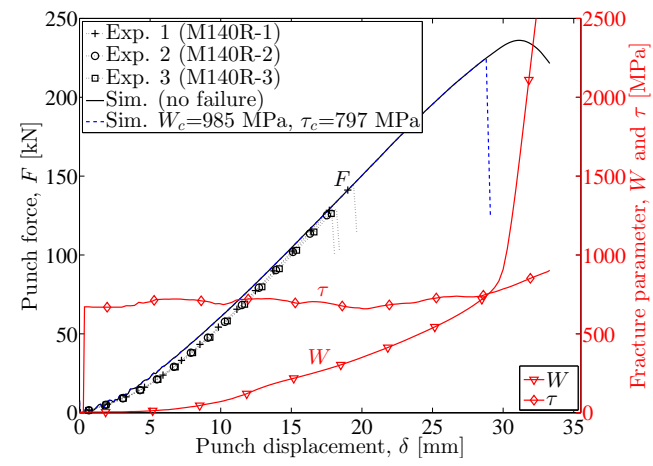

(c)

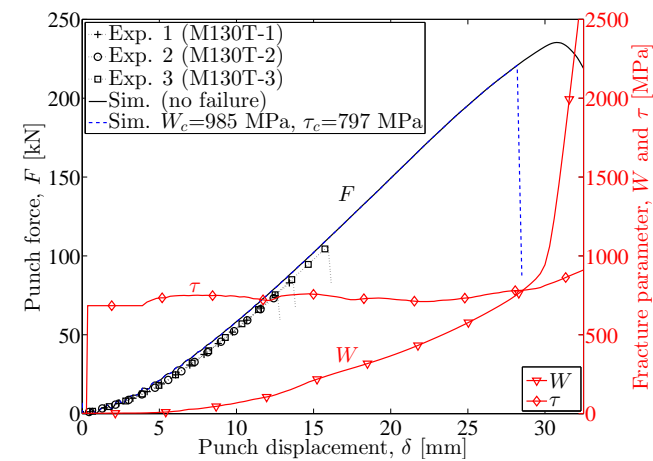

(b)



(d)

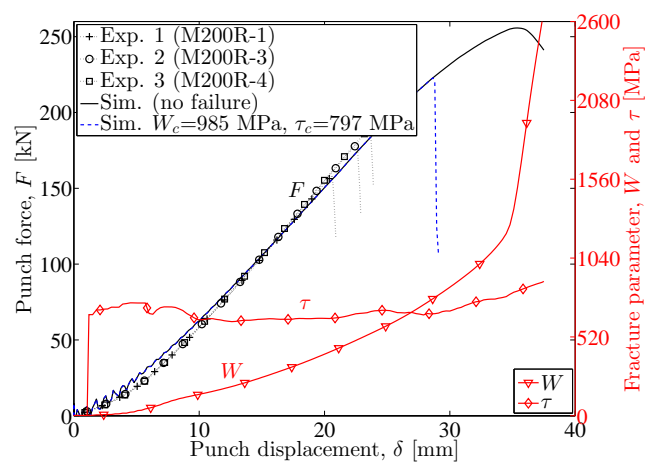

(e)

Figure 22: Results from experiments and FE simulations of the Nakajima tests for Docol $1200 \mathrm{M}$ (a) $130 \mathrm{~mm}$ waist in $R D$, (b) $130 \mathrm{~mm}$ waist in $T D$, (c) $140 \mathrm{~mm}$ waist in $R D$, (d) $130 \mathrm{~mm}$ waist in $T D$ and (e) circular. 


\section{References}

Aretz, H., 2004. Numerical restrictions of the modified maximum force criterion for prediction of forming limits in sheet metal forming. Modelling and Simulation in Materials Science and Engineering 12 (4), 677-692.

Aretz, H., 2005. A non-quadratic plane stress yield function for orthotropic sheet metals. Journal of Materials Processing Technology 168 (1), 1-9.

Bai, Y., Wierzbicki, T., 2008. A new model of metal plasticity and fracture with pressure and Lode dependence. International Journal of Plasticity 24 (6), $1071-1096$.

Bao, Y., Wierzbicki, T., 2004. On fracture locus in the equivalent strain and stress triaxiality space. International Journal of Mechanical Sciences $46(1), 81-98$.

Belytschko, T., Liu, W. K., Moran, B., 2000. Nonlinear Finite Elements for Continua and Structures. Wiley, Chichester.

Bragard, A., Baret, J.-C., Bonnarnes, H., 1972. A simplified technique to determine the FLD at the onset of necking. Report no. 33, Rapport Centre de Recherche de la Mètallurgie, Liège.

Bressan, J., Williams, J., 1983. The use of a shear instability criterion to predict local necking in sheet metal deformation. International Journal of Mechanical Sciences 25 (3), 155-168.

Cockroft, M. G., Latham, D. J., 1968. Ductility and the workability of metals. Journal of the Institute of Metals 96, 33-39.

Dieter, G. E., 1986. Mechanical Metallurgy. McGraw-Hill, New York.

Fyllingen, O., Hopperstad, O., Lademo, O.-G., Langseth, M., 2009. Estimation of forming limit diagrams by the use of the finite element method and Monte Carlo simulation. Computers and Structures 87 (1-2), 128 - 139.

Gruben, G., Fagerholt, E., Hopperstad, O., Børvik, T., 2011. Fracture characteristics of a cold-rolled dual-phase steel. European Journal of Mechanics - A/Solids 30 (3), $204-218$. 
Gurson, A., 1977. Continuum theory of ductile rupture by void nucleation and growth: Part I - yield criteria and flow rules for porous ductile media. Journal of Engineering Materials and Technology 99 (1), 2 - 15.

Hallquist, J., 2009. LS-DYNA Theory Manual. Livermore Software Technology Corporation, Livermore.

Han, H. N., Kim, K.-H., 2003. A ductile fracture criterion in sheet metal forming process. Journal of Materials Processing Technology 142 (1), 231 $-238$.

Hill, R., 1952. On discontinuous plastic states, with special reference to localized necking in thin sheets. Journal of the Mechanics and Physics of Solids 1 (1), $19-30$.

Hooputra, H., Gese, H., Dell, H., Werner, H., 2004. A comprehensive failure model for crashworthiness simulation of aluminium extrusions. International Journal of Crashworthiness 9 (5), 449 - 63.

Hora, P., Tong, L., Reissner, J., 1996. A prediction method for ductile sheet metal failure in FE-simulation. Proceedings of the 3'rd International Conference Numisheet'96, Dearborn, Michigan, 252-256.

Hosford, W., Cadell, R., 1993. Metal Forming Mechanics and Metallurgy. Prentis-Hall, New York.

Hughes, T. J. R., 2000. The Finite Element Method - Linear Static and Dynamic Finite Element Analysis. Dover Publications, Mineola, New York.

ISO, 2008. Metallic materials -sheet and strip - determination of forming limit curves - Part 2: Determination of forming limit curves in the laboratory. 12004-2:2008, Austrian Standards Institute, Wien.

Johnson, G. R., Cook, W. H., 1985. Fracture characteristics of three metals subjected to various strains, strain rates, temperatures and pressures. Engineering Fracture Mechanics 21 (1), 31 - 48.

Kim, J., Sung, J., Piao, K., Wagoner, R., 2011. The shear fracture of dualphase steel. International Journal of Plasticity 27 (10), 1658-1676. 
Lademo, O.-G., Berstad, T., Hopperstad, O. S., Pedersen, K. O., 2004a. A numerical tool for formability analysis of aluminium alloys. Part I: Theory. Steel Grips 2, 427-432.

Lademo, O.-G., Engler, O., Keller, S., Berstad, T., Pedersen, K., Hopperstad, O., 2009. Identification and validation of constitutive model and fracture criterion for AlMgSi alloy with application to sheet forming. Materials and Design 30 (8), 3005 - 3019.

Lademo, O.-G., Pedersen, K. O., Berstad, T., Hopperstad, O. S., 2004 b. A numerical tool for formability analysis of aluminium alloys. Part II: Experimental validation. Steel Grips 2, 433-437.

Larsson, R., Björklund, O., Nilsson, L., Simonsson, K., 2011. A study of high strength steels undergoing non-linear strain paths - experiments and modelling. Journal of Materials Processing Technology 211, 122-132.

Lemaitre, J., 1985. A continuous damage mechanics model for ductile fracture. Journal of Engineering Materials and Technology 107, 83-89.

Li, Y., Luo, M., Gerlach, J., Wierzbicki, T., 2010. Prediction of shear-induced fracture in sheet metal forming. Journal of Materials Processing Technology $210(14), 1858-1869$.

Marciniak, Z., Kuczynski, K., 1967. Limit strains in the processes of stretchforming sheet metal. International Journal of Mechanical Sciences 9 (9), 609-620.

Nielsen, K. B., 2000. Sheet Metal Forming Simulation using Explicit Finite Element Methods. The Sheet Metal Forming Group Department of Production, Aalborg University, Aalborg.

Olsson, K., Gladh, M., Hedin, J.-E., Larsson, J., 2006. Microalloyed highstrength steels. Advanced Materials and Processes 164 (8), 44-46.

Oyane, M., Sato, T., Okimoto, K., Shima, S., 1980. Criteria for ductile fracture and their applications. Journal of Mechanical Working Technology $4(1), 65-81$.

Pijaudier-Cabot, G., Bazant, Z. P., 1987. Nonlocal damage theory. Journal of Engineering Mechanics 113, 1512-1533. 
Shinozuka, M., Deodatis, G., 1996. Simulation of multi-dimensional Gaussian stochastic fields by spectral representation. Applied Mechanics Reviews 49, $29-53$.

Swift, H. W., 1952. Plastic instability under plane strain. Journal of the Mechanics and Physics of Solids, 1, 1-18.

Teirlinck, D., Zok, F., Embury, J., Ashby, M., 1988. Fracture mechanism maps in stress space. Acta Metallurgica 36 (5), 1213 - 1228.

Wierzbicki, T., Bao, Y., Lee, Y.-W., Bai, Y., 2005. Calibration and evaluation of seven fracture models. International Journal of Mechanical Sciences $47(4-5), 719-743$.

Wilkins, M. L., Streit, R. D., Reaugh, J. E., 1980. Cumulative-strain-damage model of ductile fracture: Simulation and prediction of engenering fracture tests. Tech. Rep. Lawrence Livermore National Laboratory, Livermore. 